\title{
Elastic Local Post-Buckling of ElLiPtical Tubes
}

\author{
N. Silvestre*,1 and L. Gardner** \\ *Department of Civil Engineering and Architecture, IST-ICIST, Technical University of Lisbon, \\ Av. Rovisco Pais, 1049-001 Lisbon, Portugal \\ ${ }^{* *}$ Department of Civil and Environmental Engineering, Imperial College London, \\ SW7 2AZ London, UK
}

\begin{abstract}
The elastic local post-buckling behaviour of elliptical tubes under compression is analysed in this paper. A brief outline of the local, distortional and global buckling behaviour of EHS tubes is firstly provided, where it is shown that local buckling modes govern the stability of short to intermediate length tubes while distortional modes control the stability of intermediate length to moderately long tubes and global buckling dominates the behaviour of longer tubes. Following this, an in-depth numerical study employing shell finite element modelling, of the elastic local post-buckling behaviour of compressed elliptical hollow section (EHS) tubes is presented. It is concluded that EHS tubes with low to moderate aspect ratio can support loads up to their limit loads but are imperfection sensitive (shell-type behaviour), while EHS tubes with moderate to high aspect ratio can carry loads higher than their limits loads (plate-type behaviour) and are imperfection insensitive. The slope of the ascending post-buckling path increases with the EHS aspect ratio and can reach values up to $40 \%$ of the slope of the linear primary path. The bound imperfection amplitude concept, separating the imperfection amplitude ranges where the EHS tube is sensitive and insensitive, is proposed. It is also found that, for increasing EHS aspect ratio, the compressive stresses grow and accumulate near the zones of minimum radius of curvature while the zones of maximum radius of curvature possess an approximately uniform and relatively low compressive stress level. Therefore, it is expected that an approach based on the effective width concept widely used for the evaluation of the strength of flat plates may be adapted to the design of EHS tubes with moderate to high aspect ratios.
\end{abstract}

Keywords: Buckling; Elliptical hollow sections (EHS); Tubes; Shells; Plates; Compression; Local buckling; Oval hollow sections (OHS); Post-buckling behaviour; Imperfection sensitivity; Aspect ratio; Critical stress; Limit stress. 


\section{Introduction}

The first investigation into the buckling behaviour of members with non-circular hollow sections (NCHS) under uniform compression is credited to Marguerre (1951), who performed a preliminary theoretical study on the buckling mode configuration of members with oval hollow section (OHS). After that, Kempner and his collaborators made consistent investigations on the buckling and post-buckling behaviour of OHS members (Kempner and Chen 1964, 1968, Feinstein et al. 1971a, b). They concluded that (i) the buckling mode maximum deflection occurs at the point of maximum radius of curvature and (ii) the buckling stress of an OHS is similar to the buckling stress of an equivalent circular hollow section (CHS) with a radius equal to the maximum radius of curvature of the OHS. In addition, Feinstein et al. (1971a, b) observed that the local buckling stress of members with OHS depended not only on the cross-section aspect ratio $\mathrm{a} / \mathrm{b}(2 \mathrm{a}$ and $2 \mathrm{~b}$ are the major and minor axis widths) but also on the length of the member under compression. Concerning the postbuckling behaviour, Kempner and Chen $(1964,1968)$ found that a decrease in the OHS thickness often leads to a more stable post-buckling behaviour and they showed that OHS members with higher aspect ratios a/b possess more stable post-buckling behaviour (like flat plates) and, conversely, OHS tubes with lower aspect ratios a/b exhibit more unstable postbuckling behaviour (like circular shells). Moreover, they also conclude that very eccentric OHS are much less sensitive to imperfections and the ultimate load may even be greater than the buckling load, which is in sharp contrast with the significant imperfection sensitivity of circular cylindrical shells. It was not until 1968 that the first investigation on the buckling and post-buckling behaviour of members with elliptical hollow sections (EHS) appeared. In this work, Hutchinson (1968) concluded that these members are imperfection-sensitive (like circular shells) but the buckling phenomenon is not catastrophic (like in circular shells) and failure may even occur at a higher load than the buckling load. However, there was no mechanically based explanation for this evidence. A few years later, Tennyson et al. (1971) also found experimentally that EHS with moderate to high eccentricity $(a / b \geq 2)$ exhibited ultimate loads higher than their buckling loads. This was attributed to the fact that highly eccentric EHS display a post-buckling behaviour more close to the plate behaviour (stable) than the circular cylindrical shell one (unstable). Later, Tvergaard (1976) examined the elastic-plastic post-buckling behaviour of OHS members under compression and found that the spread of plasticity (yielding) near the regions of maximum radius delayed and substantially eroded the post-critical strength reserve previously unveiled by Kempner and Chen for very eccentric sections. 
EHS steel tubes are now available as hot-rolled structural products (Corus 2006, Interpipe 2007) and represent an interesting solution for many visible applications in steel construction, particularly for glass facades. These shapes are included in the new edition of European Norm 10210 (CEN, 2006) and display a standard range of dimensions. In response to the emergence and commercial availability of EHS tubes, several recent investigations on their buckling behaviour and strength have been published. Gardner and Chan (2007) and Chan and Gardner $(2008,2009)$ assessed the non-linear behaviour of hot-rolled EHS tubes by means of experimental and numerical analyses and proposed structural design rules. They found that the slenderness limits for pure compression set out in EC3 for CHS classification can be safely adopted for EHS, based on the equivalent diameter of the point of the EHS with maximum radius. In addition, Zhu and Wilkinson (2007) also performed shell finite element analyses to evaluate the buckling and post-buckling behaviour of EHS in compression and compared the results with the predictions obtained by means of available formulae for equivalent CHS. Roufegarinejad and Bradford (2007) used an energy-based technique to investigate the local buckling of compressed EHS tubes with an elastic infill, while Yang at al. (2008) and Zhao and Packer (2009) studied the behaviour of concrete filled EHS in compression. Silvestre (2008) developed a formulation of Generalised Beam Theory (GBT) to analyse the elastic buckling behaviour of members with NCHS and applied it to study the behaviour of EHS shells and tubes under compression, particularly the variation of the critical buckling stress with the member length and cross-section geometry. Ruiz-Teran and Gardner (2008) have also examined the buckling response of EHS tubes in compression and proposed analytical formulae to accurately predict the critical stress. Therefore, the main objective of this work is to unveil the mechanics of the elastic local post-buckling behaviour of EHS tubes and to explain in a detailed fashion the transition between the shell-type (imperfection sensitive) behaviour of EHS tubes with low eccentricity and the plate-type (imperfection insensitive) behaviour of EHS tubes with high eccentricity.

\section{Outline of EHS buckling behaviour}

From previous investigations by the authors (Silvestre 2008; Ruiz-Teran and Gardner 2008), it was found that the stability of EHS tubes is governed by three distinct buckling modes: (i) local buckling modes, (ii) distortional buckling modes and (iii) global buckling modes. Both local and distortional buckling modes are characterized by deformation of the cross-section mid-line while global buckling is associated with overall minor-axis bending of the member. Three distinct features that characterize the differences between the local and distortional buckling modes are: 
(i) Local buckling modes do not exhibit primary warping along the cross-section mid-line, while distortional buckling modes do.

(ii) The stiffer parts of cross-sections do not displace in local buckling modes, while they (or at least some of them) do so in distortional buckling modes.

(iii) The half-wavelength of local buckling is approximately equal to the width of the most slender part of the cross-section while that of distortional buckling is several times greater.

The above distinctions between local and distortional buckling modes in EHS mirror those previously made for cold-formed steel members with flat-walled sections (FWS), which exhibit similar characteristics. The local and distortional buckling modes of EHS and FWS (in this case, a lipped channel section) are shown in Fig. 1. In both cases (EHS and FWS), the previous definitions apply. For instance, observe that the stiffer parts of these sections (the zones of maximum curvature in the EHS and the folds or corners of the lipped channel) do not displace in the local buckling modes. Conversely, in the distortional modes, the stiffer parts of the EHS and the lip folds of the FWS show significant displacements.

\begin{tabular}{|c|c|c|c|c|}
\hline & \multicolumn{2}{|c|}{ Local buckling mode } & \multicolumn{2}{|c|}{ Distortional buckling mode } \\
\hline & In-plane displacement & Warping displacement & In-plane displacement & Warping displacement \\
\hline \multicolumn{5}{|l|}{ EHS } \\
\hline FWS & & & & \\
\hline & $y$ & & & \\
\hline
\end{tabular}

Fig. 1: Local and distortional buckling modes for EHS and FWS (lipped channel)

Following a number of studies of EHS, Kempner found that a lower bound to the EHS critical local buckling stress can be obtained from the formula to calculate the critical stress for the CHS axis-symmetric buckling mode, i.e., 


$$
\sigma_{\text {cr. } 1}=\frac{E}{\sqrt{3\left(1-v^{2}\right)}}\left(\frac{t}{a^{2} / b}\right)
$$

where the CHS radius $r$ is replaced by the maximum radius of the EHS, given $b y \mathrm{a}^{2} / \mathrm{b}$ which corresponds to the least stiff regions of the EHS where the buckling lobes are located. Moreover, the half-wavelength corresponding to the critical local buckling mode is given by

$$
\mathrm{L}_{\mathrm{cr} .1}=\frac{\pi \mathrm{A} \sqrt{\mathrm{t} / \mathrm{B}}}{\sqrt[4]{12\left(1-v^{2}\right)}}
$$

Fig. 2 shows the variation of the ratio $\sigma_{\mathrm{cr}} / \sigma_{\mathrm{cr} .1}$ with the ratio $\mathrm{L} / \mathrm{L}_{\mathrm{cr} .1}$ (logarithmic scale) for a typical EHS steel tube with $\mathrm{E}=210000 \mathrm{~N} / \mathrm{mm}^{2}$ and $v=0.3$ and geometrically characterised by $a=150 \mathrm{~mm}, b=100 \mathrm{~mm}$, and $t=6 \mathrm{~mm}$. In this figure, $\sigma_{c r}$ is the exact value of the EHS critical stress, $\sigma_{\text {cr.1 }}$ is the approximate value of the EHS critical stress calculated by means of the CHS formula (Eq. (1)), L is the tube length and $\mathrm{L}_{\mathrm{cr} .1}$ is the approximate value of the critical half-wavelength calculated by means of the CHS formula (2). From Fig. 2, it may be observed that:

(i) EHS tubes with short to intermediate lengths buckle in local critical modes, which are characterised by two buckling lobes, each one located in the minor axis region of the section, where the maximum local radius of curvature is found. These regions of an elliptical section are geometrically less stiff than those of minimum radius of curvature found near the major axis and, they, therefore, trigger the onset of instability. The several local minima shown in Fig. 2 correspond to an increasing number of longitudinal halfwaves of short wavelength with increasing tube length.

(ii) For intermediate to moderately long EHS tubes, critical buckling takes place principally in distortional modes, characterised by the occurrence of simultaneous cross-section warping and transverse deformation of its entire contour. In this region, the minima seen in Fig. 2 correspond to distortional buckling modes which exhibit fewer longitudinal half-waves than the local modes and of longer wavelength (approximately fourteen times that of the local modes for the section considered - see previous item (iii)).

(iii) For long EHS tubes, the critical buckling mode is overall minor axis flexural buckling where the critical load reduces with member length.

It may also be seen that Eq. (1) provides a lower bound to the critical buckling stress of an EHS in the local mode (12\% lower for the section considered) while it gives an upper bound of the 
critical buckling stress of an EHS in the distortional mode ( $4 \%$ higher for the section considered). Moreover, Eq. (2) gives a precise estimate of the critical half-wavelength of the EHS local mode.

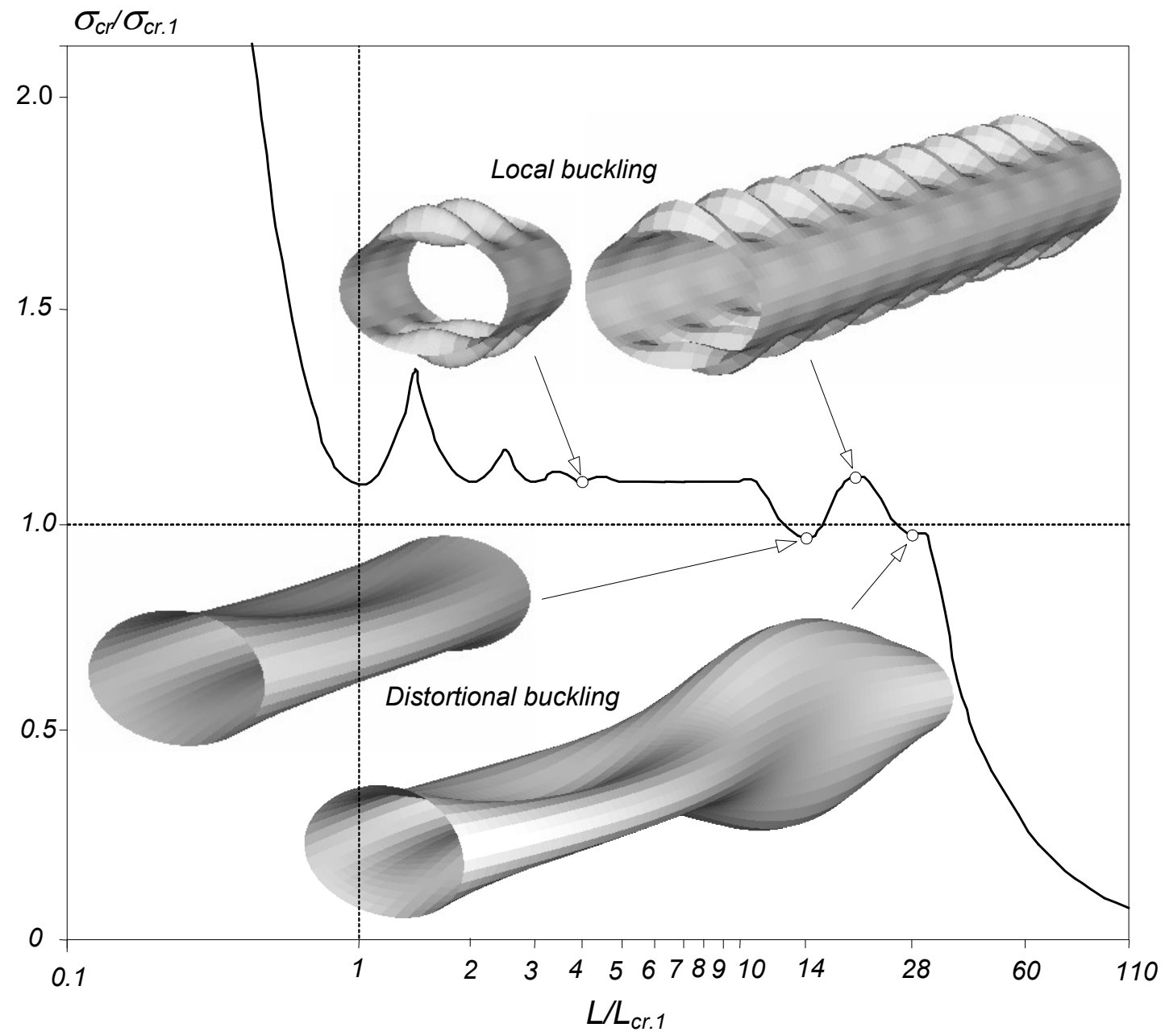

Fig. 2: Variation of the EHS tube critical stress $\sigma_{\mathrm{cr}}$ with the length L.

Variation of the critical stress $\sigma_{\mathrm{cr}}$ and the buckling mode nature with the cross-section dimensions (thickness $\mathrm{t}$ and aspect ratio $\mathrm{a} / \mathrm{b}$ ) has also been investigated (Silvestre, 2008; Ruiz-Teran and Gardner, 2008). It was found that:

(i) For thinner EHS tubes, Eq.(1) provides a more accurate prediction of the exact critical buckling stress.

(ii) With increasing thickness, both length ranges where the local and the distortional buckling modes are critical decrease, this drop being more substantial for the local mode length range than for the distortional mode length range. Also, for increasing thickness values, the critical stress for the local buckling modes increases more substantially than for the distortional modes. From these observations, it can be concluded that increasing thickness leads to a higher relevance of the distortional buckling modes, in comparison with the local modes. The thickness has only a minor effect on the global buckling mode. 
(iii) For increasing aspect ratio $a / b$, the length ranges over which the local buckling mode and distortional mode take place remains essentially unaltered. For increasing aspect ratio $\mathrm{a} / \mathrm{b}$, the local and distortional critical buckling stresses become closer and tend to be very similar for high $\mathrm{a} / \mathrm{b}$ values.

On the basis of the described previous studies, the elastic critical buckling behaviour of EHS tubes is now fairly well understood. However, other than the familiar case of flexural buckling with insignificant post-buckling stiffness for long tubes, the elastic local and distortional post-buckling behaviour of short and intermediate length elliptical tubes warrants further attention. The former (elastic local post-buckling) is therefore the focus of the present paper.

\section{Elastic Local Post-buckling Behaviour}

The main objective of this section is to examine the elastic local post-buckling behaviour of EHS tubes under compression. In particular, an in-depth study on the influence of the EHS aspect ratio on the variation and nature of the post-buckling equilibrium path, ensuing stress distributions and imperfection sensitivity is presented. A reference EHS stub column with length $\mathrm{L}=300 \mathrm{~mm}$, thickness $\mathrm{t}=4 \mathrm{~mm}$ and fully fixed supports is considered. The EHS geometry is characterised by the major axis width $2 \mathrm{a}$ and minor axis width $2 \mathrm{~b}$, which are considered here as the dimensions of the EHS mid-line (i.e., $2 \mathrm{a}+\mathrm{t}$ and $2 \mathrm{a}+\mathrm{t}$ are the outer dimensions). Based on a commercially available (Corus, Interpipe) reference geometry ( $2 \mathrm{a}=$ $150 \mathrm{~mm}, 2 \mathrm{~b}=75 \mathrm{~mm}, \mathrm{a} / \mathrm{b}=2.0$ ), five further EHS configurations were generated and studied. These were obtained by (i) keeping the cross-section perimeter unaltered $(\mathrm{P}=363$ $\mathrm{mm}$ ) and (ii) varying the aspect ratio $\mathrm{a} / \mathrm{b}$ from 1.10 to 5.0. The six EHS geometries considered in this paper are represented in Fig. 3 and are characterised by an equal crosssection area $A=1450 \mathrm{~mm}^{2}$ and thus an equal amount of steel in each column.

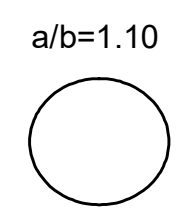

$2 \mathrm{a}=121.0 \mathrm{~mm}$ $2 \mathrm{~b}=110.0 \mathrm{~mm}$

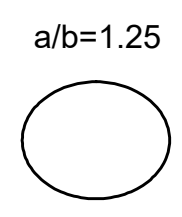

$2 \mathrm{a}=128.0 \mathrm{~mm}$ $2 \mathrm{~b}=102.4 \mathrm{~mm}$

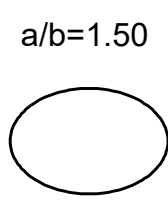

$2 \mathrm{a}=137.4 \mathrm{~mm}$ $2 b=91.6 \mathrm{~mm}$

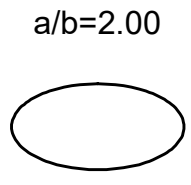

$2 \mathrm{a}=150.0 \mathrm{~mm}$ $2 \mathrm{~b}=75.0 \mathrm{~mm}$

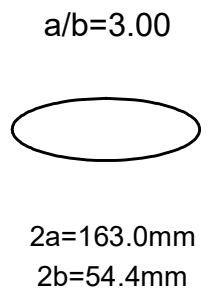

$2 \mathrm{~b}=54.4 \mathrm{~mm}$

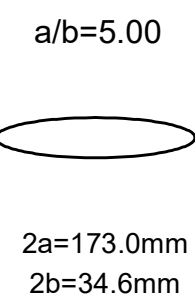

$2 \mathrm{~b}=34.6 \mathrm{~mm}$

Fig. 3: Selected EHS geometries and corresponding aspect ratio a/b. 


\subsection{Shell finite element model}

The local post-buckling behaviour of EHS tubes under compression is investigated numerically using the finite element code ABAQUS (DS Simulia 2007). The following issues are addressed: (i) stub column discretisation, (ii) modelling of the stub column end support conditions, applied loads and material behaviour, (iii) incorporation of initial geometrical imperfections and (iv) the numerical techniques employed to solve both the linear eigenvalue buckling problem and the system of algebraic non-linear equations providing the postbuckling equilibrium paths.

\subsubsection{FE discretisation}

In order to analyse the local behaviour of a given thin-walled member, one must adopt a twodimensional model to discretise its mid-surface, a task that can be adequately performed by means of 4-node isoparametric shell element with reduced integration (S4R elements in the ABAQUS nomenclature). In the case of the EHS tubes dealt with in this work, discretisation of the cross-section into 36 finite elements was found to be sufficient - this corresponds roughly to adopting $10 \mathrm{~mm}$ wide elements. A mesh size of $5 \mathrm{~mm} \times 10 \mathrm{~mm}$ in the length direction was used, leading to a total of 2160 elements and 2196 nodes.

\subsubsection{End support conditions}

In order to ensure adequate modelling of the fixed end support conditions, rigid plates were attached to the stub column end sections, thus preventing all local and global displacements and rotations, including (i) rigid-body motions (with the exception of the axial translation of the loaded end section), (ii) warping and (iii) in-plane deformation. These rigid end plates were modelled by means of 3-node R3D3 finite elements (again ABAQUS nomenclature).

\subsubsection{Loading and material}

The compressive load was applied through the centroid of the axially free end section and, in order to obtain the load versus axial shortening equilibrium path, the corresponding axial displacement was assessed by using an ABAQUS command termed "MONITOR". The material behaviour of the steel tube was assumed to be homogeneous, isotropic and linear elastic, which is fully characterised by the values of Young's modulus $\left(E=210000 \mathrm{~N} / \mathrm{mm}^{2}\right)$ and Poisson's ratio $(v=0.3)$.

\subsubsection{Initial imperfections}


Initial geometrical imperfections can be incorporated into an ABAQUS nonlinear analysis either manually, by directly inputting an arbitrary initial deformed configuration, or automatically, through the a priori definition of a linear combination of normalised buckling mode shapes, yielded by a preliminary buckling analysis based on a finite element mesh identical to the one adopted to perform the post-buckling analysis. Since there are only limited available data concerning initial geometric imperfections of EHS tubes (Chan and Gardner 2008, 2009), the ones considered in this work were included automatically and consist of the most relevant (critical) local buckling mode shapes, incorporated into the tube initial geometry by means the initial conditions ABAQUS command. Therefore, preliminary buckling (eigenvalue) analyses were carried out for all the six columns in order to obtain the local buckling stress values and the corresponding buckling mode configurations, which are depicted in Fig. 4. It should be noted that several buckling modes often appeared in the close vicinity of the critical one, as is typical in shell buckling analyses. The critical buckling modes represented in Fig. 4 were selected in order to achieve consistency between all six deformed configurations based on the following criteria: (i) symmetry of cross-section deformation (in Fig. 4 the hidden part of the column deforms in the same way as the visible part), (ii) an odd number of longitudinal half-waves along the column length and (iii) the point of maximum local radius of curvature at the mid-span cross-section (the point of initiation of instability) moves inward. Consistency in the choice of buckling mode is crucial for allowing a proper comparison between the post-buckling behaviour of the six columns, since the geometrical imperfection employed in the post-buckling analysis takes the form of the critical buckling mode shape. For the initial studies, a small imperfection amplitude equal to $0.1 \mathrm{~mm}$ (2.5\% of the EHS thickness) was adopted, while imperfection sensitivity is investigated further in Section 4.4 of this paper. Clause D.1.2.2 of EC3 Part 1.6 (CEN 2007) states that the characteristic imperfection amplitude $\Delta \mathrm{w}_{\mathrm{k}}$ in circular shells should be taken as

$$
\Delta \mathrm{w}_{\mathrm{k}}=\frac{\mathrm{t}}{\mathrm{Q}} \sqrt{\frac{\mathrm{r}}{\mathrm{t}}}
$$

Since the primary objective of the present work is to unveil the local post-buckling behaviour of EHS tubes, it is desirable to employ a small imperfection amplitude, but with a practical (design) basis. Thus, the minimum value of $\Delta \mathrm{w}_{\mathrm{k}}=0.023 \mathrm{t}$ (i.e. $2.3 \%$ of the EHS thickness) was found for the tube with $a / b=5.0$, using the minimum EHS radius $r_{\min }=b^{2} / a=17.3 \mathrm{~mm}$ and a fabrication quality parameter $\mathrm{Q}=40$ (class $\mathrm{A}$ ). The obtained limit value accords with the chosen value of imperfection amplitude for the numerical study $(0.1 \mathrm{~mm})$. 


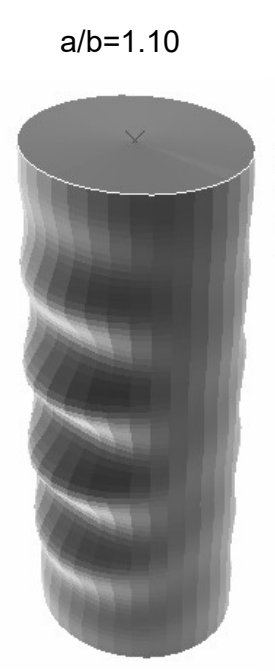

$\sigma_{\mathrm{cr}}=7938$

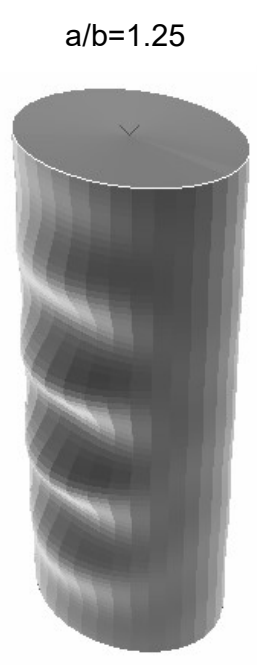

$\sigma_{\mathrm{cr}}=6843$

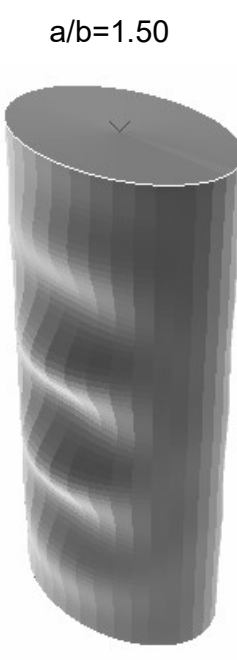

$\sigma_{\mathrm{cr}}=5535$

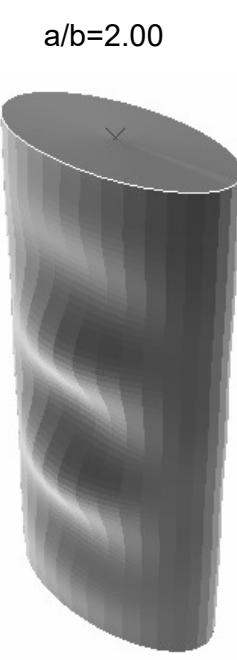

$\sigma_{\mathrm{cr}}=4004$

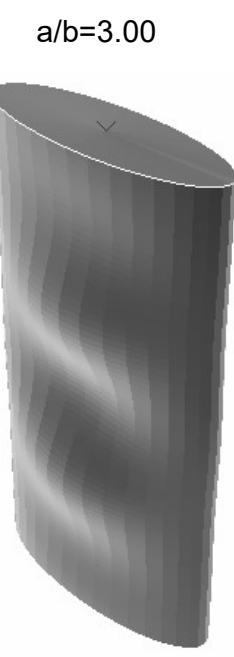

$\sigma_{\mathrm{cr}}=2600$ $a / b=5.00$

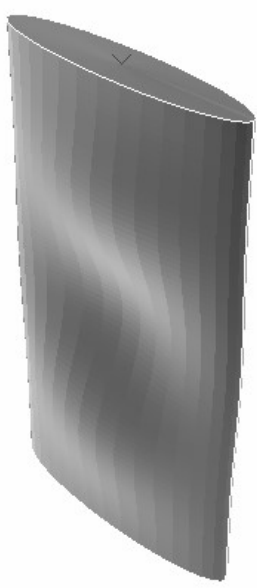

$\sigma_{\mathrm{cr}}=1508$

Fig. 4: Critical buckling modes and corresponding critical stresses $\sigma_{\mathrm{cr}}\left(\right.$ in $\mathrm{N} / \mathrm{mm}^{2}$ )

\subsubsection{Residual stresses}

No residual stresses were incorporated into the numerical analyses, since they were deemed to be of very low magnitude in hot-finished elliptical tubes (Chan and Gardner 2008). In addition, the behaviour and collapse of thinner EHS tubes manufactured by cold-rolling processes are relatively insensitive to residual stresses and it is current practice to neglect their influence on the post-buckling behaviour and ultimate strength of cold-formed steel members.

\subsubsection{Solution technique}

Performing a linear buckling analysis requires solving an eigenvalue problem, defined by the tube (discretised) elastic and geometric stiffness matrices. This task is performed by means of the sub-space iteration method. Since several local buckling modes appear with similar buckling stresses (some of them nearly coincident), it is worth requesting a larger number of buckling modes from the ABAQUS analyses in order to avoid mixed configurations of the lower buckling modes (including the critical one). These mixed configurations arise from the numerical (multiple) solution of the eigenvalue problem. The non-linear (post-buckling) equilibrium paths, relating the applied compressive load with the tube axial shortening, are obtained by means of an incremental-iterative technique that employs Newton-Raphson's method and adopts Riks's arc-length control strategy - this is done automatically in ABAQUS, on the basis of a pre-defined 'calibration' increment and tolerance parameters. 


\subsection{Non-linear equilibrium paths}

Before introducing the study on the influence of the EHS aspect ratio on the variation and nature of the post-buckling equilibrium path and ensuing stress distributions, the variation of the local critical buckling stress with the EHS aspect ratio $a / b$ is first assessed. Values of the critical buckling stress $\sigma_{\mathrm{cr}}$ for the six different aspect ratios considered are represented in Fig. 5 by the solid circles. As expected, it may be seen that the critical stress decreases with increasing aspect ratio, almost inversely. Based on the Kempner formula (Eq. (1)), an approximate expression to estimate the value of $\sigma_{\mathrm{cr}}$ was recently proposed (Silvestre 2008) and reads,

$$
\sigma_{\text {cr. } 2}=\frac{\mathrm{E}}{\sqrt{3\left(1-v^{2}\right)}}\left(\frac{\mathrm{t}}{\mathrm{a}^{\alpha} / \mathrm{b}}\right) \quad \alpha=0.05 \frac{\mathrm{b}}{\mathrm{a}}+1.95
$$

The estimates $\sigma_{\text {cr.1 }}$ given by the Kempner formula (Eq. (1)) were compared to the numerically generated critical stresses and found to be accurate for EHS with low aspect ratios, but became very conservative for moderate to high aspect ratios. The predictions $\sigma_{\text {cr.2 }}$ given by the Silvestre formula (Eq. (4)) were found to be better than those obtained from the Kempner formula, though increasing errors still resulted for higher aspect ratios. Recently, Ruiz-Teran and Gardner (2008) also proposed the following analytical formulae to calculate the critical stress in EHS tubes

$$
\begin{array}{ll}
\sigma_{\text {cr.3 }}=\frac{\mathrm{E}}{\sqrt{3\left(1-v^{2}\right)}} \frac{2 \mathrm{t}}{\mathrm{D}_{\mathrm{Eq}}} \mathrm{C}_{\mathrm{x}, \mathrm{EHS}} & \mathrm{D}_{\mathrm{Eq}}=2 \mathrm{a}+2 \mathrm{a}\left(1-2.3\left(\frac{\mathrm{t}}{2 \mathrm{a}}\right)^{0.6}\right) \cdot\left(\frac{\mathrm{a}}{\mathrm{b}}-1\right) \\
\mathrm{C}_{\mathrm{x}, \mathrm{EHS}}= \begin{cases}1-\left(1-\mathrm{C}_{\mathrm{x}}\right)\left(\frac{2.5-(\mathrm{a} / \mathrm{b})}{1.5}\right)^{2} \text { if } \mathrm{a} / \mathrm{b}<2.5 & \mathrm{C}_{\mathrm{x}}=1+\frac{0.2}{6}\left(1-4 \sqrt{2} \frac{\mathrm{L}}{2 \mathrm{a}} \sqrt{\frac{\mathrm{t}}{2 \mathrm{a}}}\right) \\
1 \text { if } \mathrm{a} / \mathrm{b} \geq 2.5 & \end{cases}
\end{array}
$$

The $\mathrm{C}_{\mathrm{x} \text {,EHS }}$ parameter allows for length effects and is based on modified expressions for CHS tubes presented in EC3 Part 1.6 (CEN 2007). The critical stress prediction $\sigma_{\text {cr.3 }}$ proposed by Ruiz-Teran and Gardner (Eq. (5)) is more complex than that presented by Silvestre (Eq. (4)), but was found to be accurate over the full range of aspect ratios considered. With the focus of the present paper being elastic post-buckling of EHS, comparisons between closed-form solutions and FE results for elastic buckling are not shown here. The interested reader is referred to Silvestre (2008) and Ruiz-Teran and Gardner (2008) for further details. 


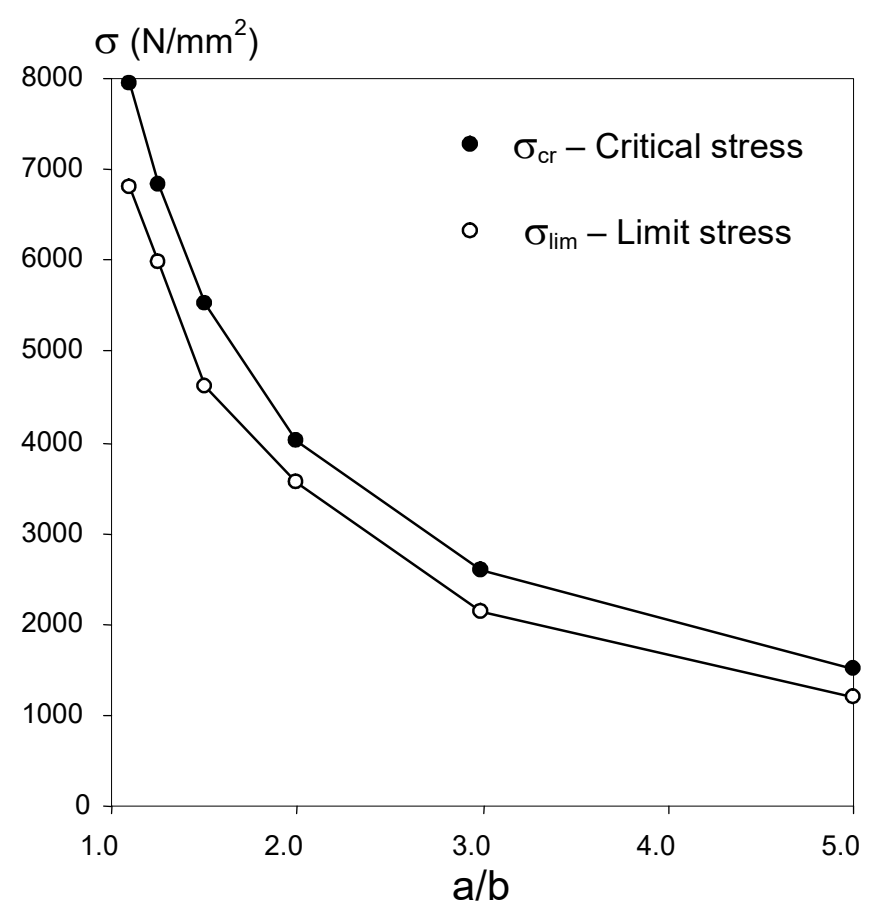

Fig. 5: Variation of critical $\sigma_{c r}$ and limit $\sigma_{\lim }$ stresses with the aspect ratio $a / b$.

Having examined the elastic critical buckling behaviour of EHS, subsequent studies of the elastic post-buckling behaviour were then performed. The non-linear equilibrium paths (applied stress $\sigma$ versus axial shortening $\mathrm{u}$ ) obtained from the post-buckling analyses are plotted in Fig. 6). The same results are presented in a normalised format - critical stress ratio $\sigma / \sigma_{\mathrm{cr}}$ versus critical strain ratio $\varepsilon / \varepsilon_{\mathrm{cr}}-$ in Fig. 7. 


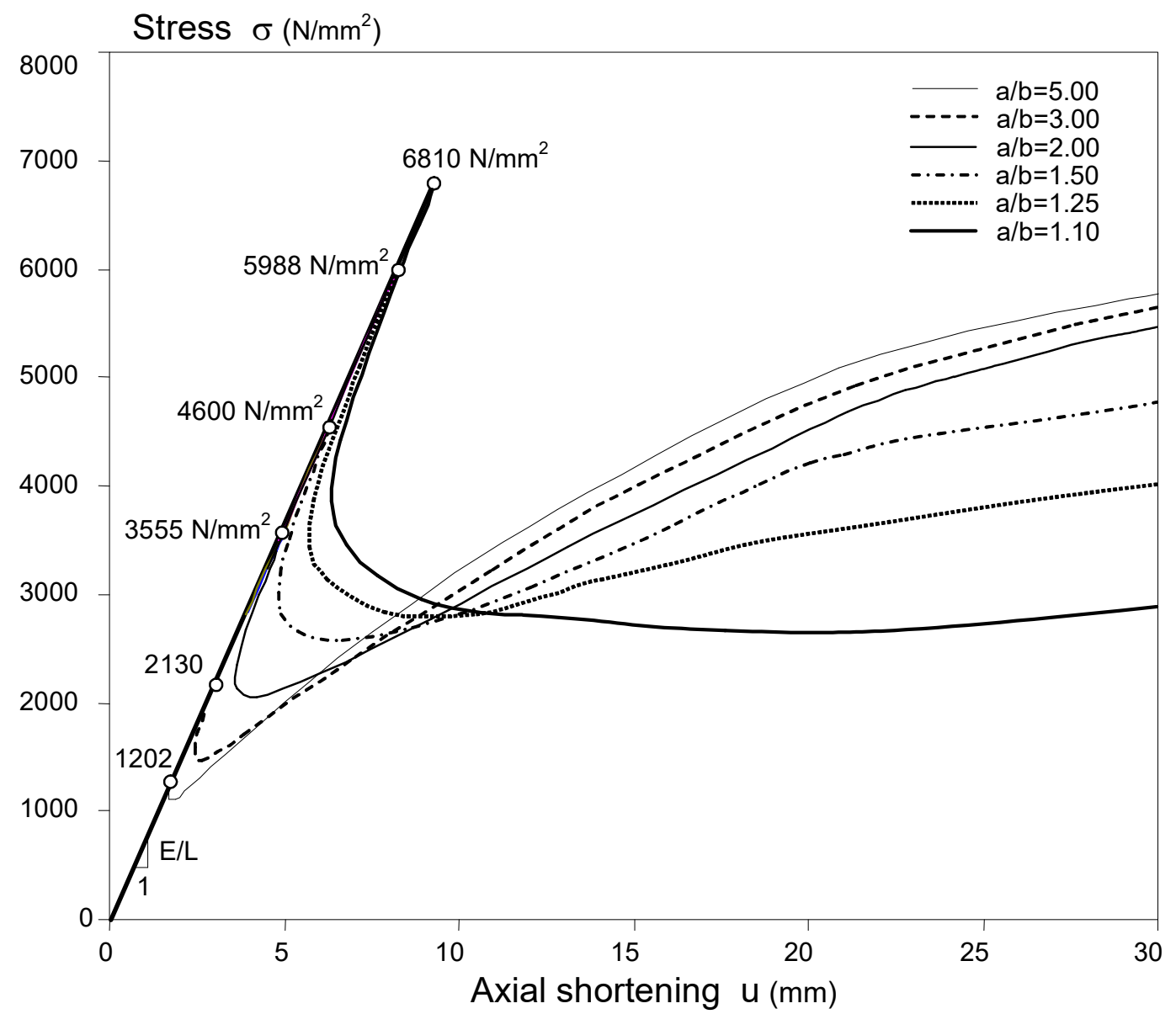

Fig. 6: Relationship between applied stress and axial shortening $\mathrm{u}$ for varying aspect ratio $\mathrm{a} / \mathrm{b}$.

From careful observation of Figs. 6 and 7 the following comments can be made:

(i) The six tubes possess an equal cross-section area and, therefore, the slope of the primary path is given by $\mathrm{E} / \mathrm{L}$ and is equal for all six tubes; the primary paths are also perfectly linear until the limit stress $\sigma_{\text {lim }}$ is reached. As expected, the limit stress $\sigma_{\text {lim }}$ is lower than the corresponding critical stress $\sigma_{\text {cr }}$ due to influence of the imperfections. The variation of limit stress $\sigma_{\lim }$ with aspect ratio is shown in Table 1 and Fig. 5 (unfilled circles). It may be observed that the decrease in $\sigma_{\lim }$ values with increasing $a / b$ values is very similar to that of the critical stress, shown by the solid circles in Fig. 5. In fact, the ratio between the limit stress and the critical stress $\left(\sigma_{\lim } / \sigma_{\mathrm{cr}}\right)$ shows little variation with $\mathrm{a} / \mathrm{b}$ and remains around 0.85 for the adopted imperfection amplitude of $2.5 \%$ of the EHS thickness. This suggests that the imperfection sensitivity of EHS tubes is not strongly dependent on the aspect ratio $\mathrm{a} / \mathrm{b}$ of the cross-section, within the examined range of 1.10 $<\mathrm{a} / \mathrm{b}<5.00$. 


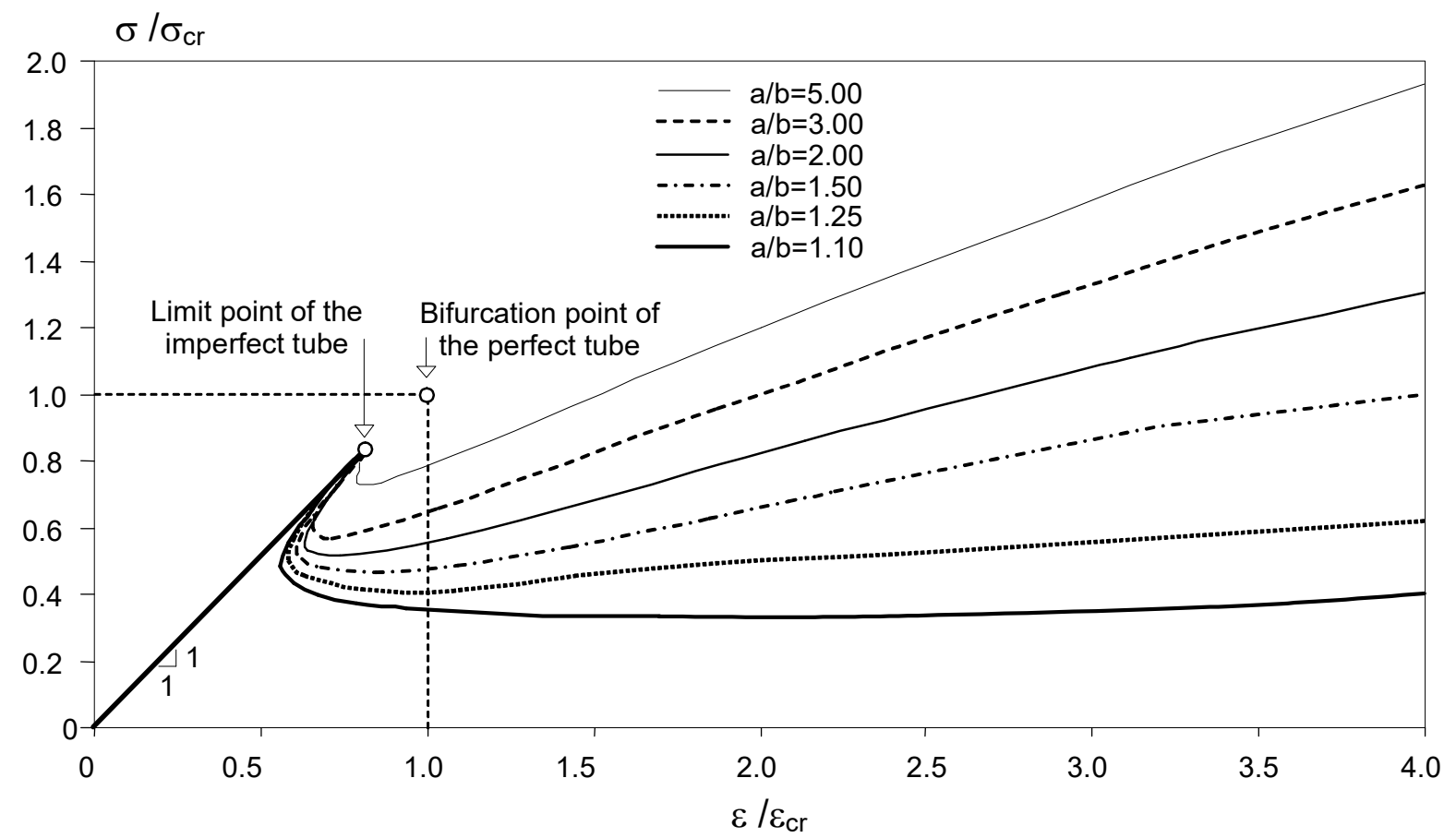

Fig. 7: Relationship between the critical stress ratio $\left(\sigma / \sigma_{\mathrm{cr}}\right)$ and critical strain ratio $\left(\varepsilon / \varepsilon_{\mathrm{cr}}\right)$ for varying $a / b$.

(ii) After reaching the limit stress $\sigma_{\text {lim, }}$ the six non-linear paths show very distinct formats. The descending branch (decrease of both applied stress and axial shortening) is much more pronounced for tubes with lower aspect ratio $a / b$, as shown in the graph of $\sigma / \sigma_{\mathrm{cr}}$ versus $\varepsilon / \varepsilon_{\text {cr }}$ given in Fig. 7 . In order to quantify this tendency, it is necessary to determine the "bifurcation angle" $\phi$, which is the angle formed by the two equilibrium paths (stable and unstable) at the bifurcation point of the non-dimensionalised curves $\sigma / \sigma_{\mathrm{cr}}$ versus $\varepsilon / \varepsilon_{\mathrm{cr}}$. The bifurcation angle (in degrees) is given by

$$
\phi=\arctan \left(\frac{\Delta\left(\frac{\sigma}{\sigma_{\mathrm{cr}}}\right)}{\Delta\left(\frac{\varepsilon}{\varepsilon_{\mathrm{cr}}}\right)}\right)-45^{\circ}
$$

where the decrements $\Delta$ are related to the post-critical unstable (or descending) path. Table 1 shows the values of $\phi$ for the six tubes, while Fig. 8(a) depicts the variation of bifurcation angle with aspect ratio. It is clearly shown that the values of the bifurcation angle grow with the aspect ratio $a / b$; this increase being more substantial for EHS with moderate to high aspect ratio $(a / b \geq 2)$ than for EHS with low to moderate aspect ratio $(\mathrm{a} / \mathrm{b} \leq 2)$ - see Fig. 8(a). This finding gives a preliminary indication of the severity of the unstable response and the ability to return to a stable branch. 
(iii) Fig. 6 shows that all the tubes exhibit post-critical curves that possess local minima, which move horizontally towards the linear primary path as the aspect ratio increases. Beyond the local minima the post-buckling paths (for $\mathrm{a} / \mathrm{b} \geq 1.10$ ) exhibit a positive slope (increase in applied stress and axial shortening) and are stable. The maximum value of the slope is given by

$$
\Delta_{\max }=\max _{\mathrm{i}} \frac{\Delta\left(\frac{\sigma}{\sigma_{\mathrm{cr}}}\right)_{\mathrm{i}}}{\Delta\left(\frac{\varepsilon}{\varepsilon_{\mathrm{cr}}}\right)_{\mathrm{i}}}
$$

where the increments $\Delta$ are related to the ascending (stable) post-buckling path. The values of $\Delta_{\max }$ (for strains up to four times the critical buckling strain $\varepsilon_{\mathrm{cr}}$ ) are shown in Table 1 and their variation with the aspect ratio is represented in Fig. 8(b). Noting that the slope of the primary linear path is $\Delta=1$, it may be observed that the maximum slope of the ascending post-buckling branch increases with aspect ratio $\mathrm{a} / \mathrm{b}$, this increase being more substantial for low to moderate aspect ratios $(\mathrm{a} / \mathrm{b} \leq 2)$ and less pronounced for moderate to high aspect ratio $(a / b \geq 2)$ - see Fig. 8(b). Furthermore, the slope of the ascending post-buckling path can reach values up to $40 \%$ of the initial slope of the linear primary path; a value similar to that for flat simply-supported plates with unrestrained edges.

(iv) From points (i) to (iii), it may be concluded that the maximum applied stress $\sigma_{\max }$ that an elastic EHS tube with low to moderate aspect ratio $(\mathrm{a} / \mathrm{b} \leq 1.5)$ can support is its limit stress $\sigma_{\lim }$ whereas, the maximum applied stress $\sigma_{\max }$ that an elastic EHS tube with moderate to high aspect ratio $(\mathrm{a} / \mathrm{b} \geq 2.0)$ can carry is higher than its limit stress $\sigma_{\text {lim }}$ (see Fig. 6). As mentioned in the introduction, this behaviour was first observed by Kempner and Chen (1964, 1968) and Hutchinson (1968). The initially unstable post-buckling response exhibited by all six tubes investigated (with an imperfection of $2.5 \%$ of the section thickness), means that snap-through behaviour is experienced at the limit stress. However, Fig. 6 shows that the severity of the snap-through reduces with increasing aspect ratio $\mathrm{a} / \mathrm{b}$. For instance, the very eccentric tube with $\mathrm{a} / \mathrm{b}=5.0$ experiences, at the limit stress level $\sigma_{\text {lim }}=1202 \mathrm{~N} / \mathrm{mm}^{2}$, a very small snap between $\mathrm{u}=1.86 \mathrm{~mm}$ and $\mathrm{u}=$ $2.22 \mathrm{~mm}$. Conversely, the moderately eccentric tube with $\mathrm{a} / \mathrm{b}=2.0$ experiences, at the limit stress level $\sigma_{\text {lim }}=3555 \mathrm{~N} / \mathrm{mm}^{2}$, a larger snap between $\mathrm{u}=4.98 \mathrm{~mm}$ and $\mathrm{u}=12.85$ mm. 
Table 1. Limit stress, bifurcation angle and maximum slope of post-buckling paths for EHS of varying aspect ratio.

\begin{tabular}{|c|c|c|c|c|c|}
\hline $\mathrm{a} / \mathrm{b}$ & $\sigma_{\mathrm{cr}}\left(\mathrm{N} / \mathrm{mm}^{2}\right)$ & $\sigma_{\lim }\left(\mathrm{N} / \mathrm{mm}^{2}\right)$ & $\sigma_{\lim } / \sigma_{\mathrm{cr}}$ & $\phi\left(^{\circ}\right)$ & $\Delta \max$ \\
\hline 1.10 & 7938 & 6810 & 0.86 & 4.1 & 0.023 \\
\hline 1.25 & 6843 & 5988 & 0.88 & 4.3 & 0.119 \\
\hline 1.50 & 5535 & 4600 & 0.83 & 5.2 & 0.215 \\
\hline 2.00 & 4004 & 3555 & 0.89 & 6.5 & 0.276 \\
\hline 3.00 & 2600 & 2130 & 0.82 & 12.0 & 0.351 \\
\hline 5.00 & 1508 & 1202 & 0.80 & 33.1 & 0.411 \\
\hline
\end{tabular}

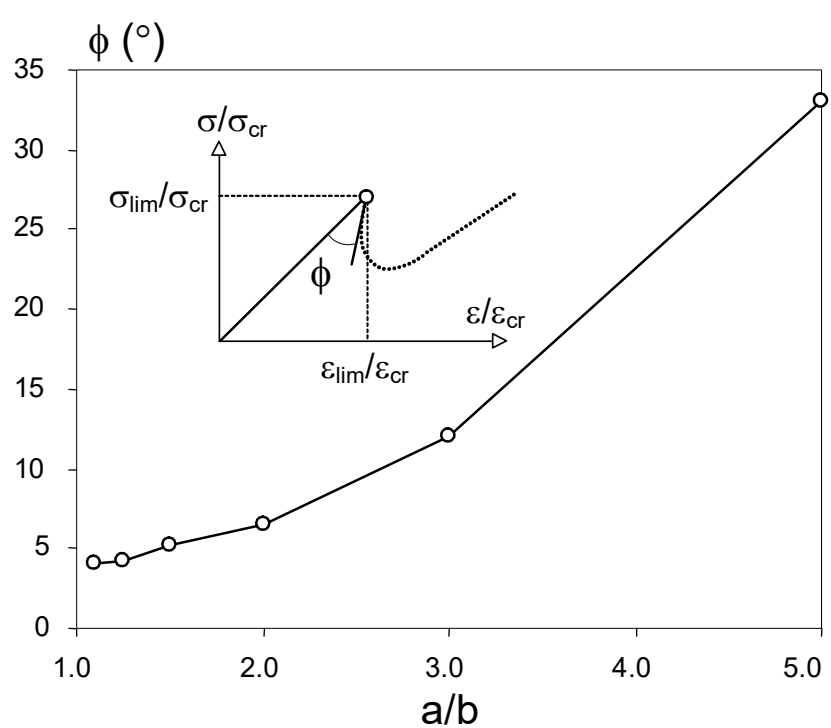

(a)

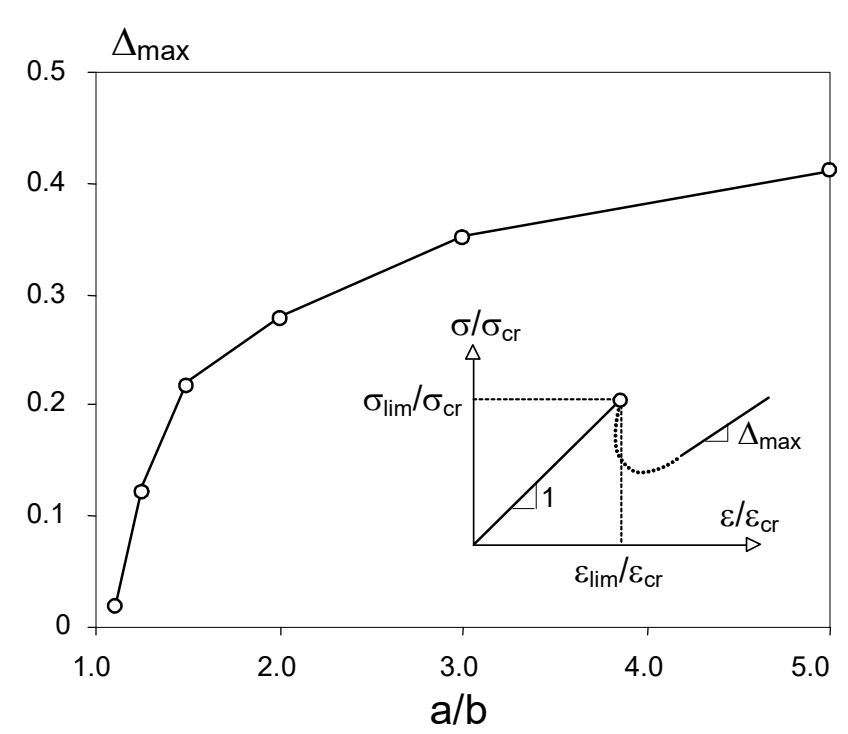

(b)

Fig. 8: Variation of (a) the bifurcation angle $\phi$ and (b) the maximum slope $\Delta_{\max }$ of the ascending path with aspect ratio.

The deformed configurations of the EHS tubes in the post-buckling regimes are shown in Fig. 9, where deformation may be seen to be concentrated towards the mid-height of the specimens. Initial geometrical imperfections were imposed with an inward deformation of the flatter region (i.e. maximum local radius of curvature) of the EHS at mid-height (see Fig. 3). From Fig. 9, it may be seen that the post-buckling deformed configurations are characterised by a pronounced flattening of the cross-section at its mid-height; this flattening is associated with high tensile normal stresses that develop in the transverse (circumferential) direction.

Since only elastic local buckling imperfection shapes were considered in this study, the influence of other initial imperfection shapes (e.g. distortional or global buckling modes or other arbitrary pattersn) to the post-buckling failure mode was not assessed. However, it may be observed that columns with lower cross-sectional aspect ratios $(\mathrm{a} / \mathrm{b})$ had local imperfection shapes with several longitudinal half-waves (see Fig. 4) and had a failure mode with a 
localized kink at mid-height (see Fig. 9). Conversely, the columns with higher aspect ratios had local imperfection shapes with fewer longitudinal half-waves (see Fig. 4) and a failure mode with a more widespread buckle at the mid-height (see Fig. 9).

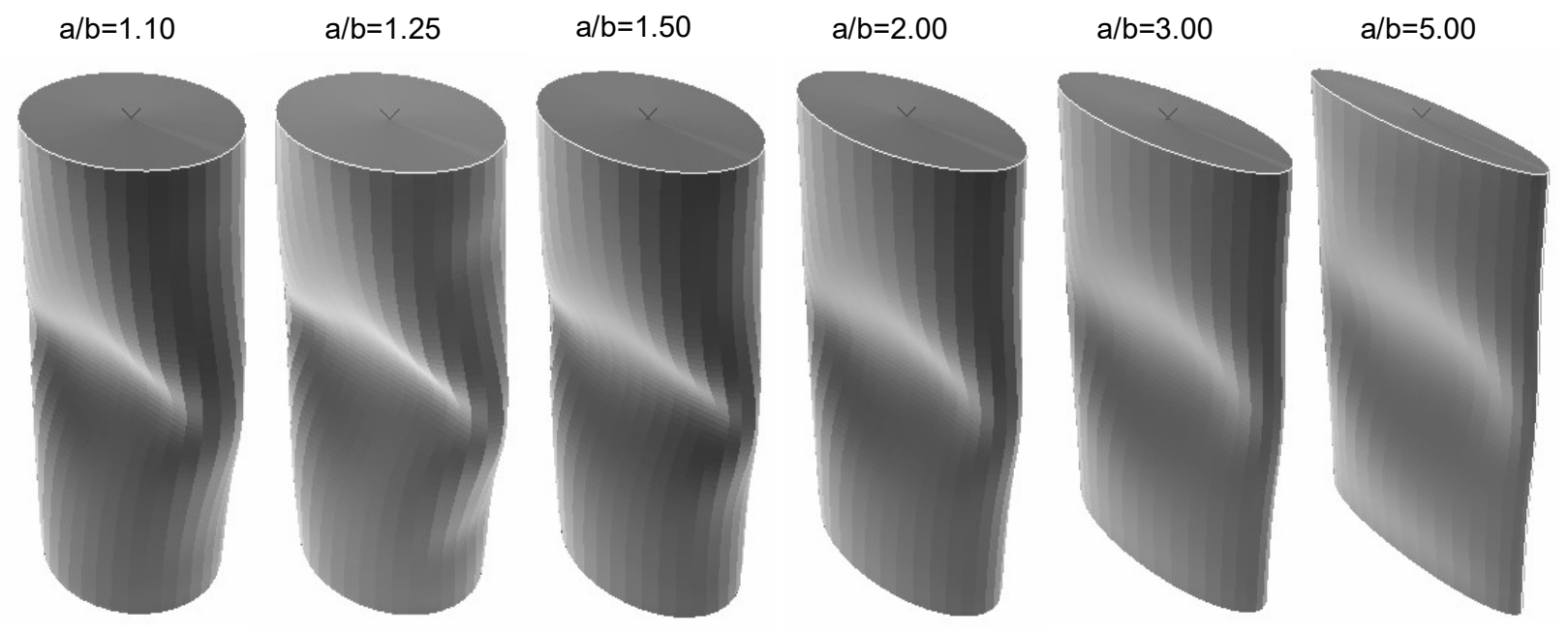

Fig. 9: Deformed configurations of the EHS tubes in the post-buckling regime.

\subsection{Normal stress distributions}

In order to explain the distinct post-critical behaviour exhibited by EHS tubes and its dependency on the aspect ratio $a / b$, the normal stress distributions in the weakest (most deformed) zone of the tube, (i.e., at mid height) are examined. Fig. 10 comprises six graphs (for the six different aspect ratios investigated), each one showing the evolution of normal stress distributions $\sigma(\theta)$ for several load levels $\left(\sigma / \sigma_{\mathrm{cr}}\right)$, i.e., for several points travelling along the equilibrium path. In each figure, the presented values of $\sigma / \sigma_{\mathrm{cr}}$ initially increase until the limit point is reached, after which the values decrease towards the local minimum and finally increase again after this point); compressive stresses are positive. The normal stress $\sigma(\theta)$ is measured along the mid-line of the EHS and associated with membrane behaviour and $\theta$ is the angle to the centre of the EHS; $\left(\theta=0^{\circ}\right.$ and $180^{\circ}$ correspond to the points of minimum radius of curvature $r_{\min }=b^{2} / a$, coincident with the EHS major axis, and $\theta=90^{\circ}$ and $270^{\circ}$ correspond to the points of maximum radius of curvature $r_{\max }=a^{2} / b$, coincident with the EHS minor axis). The solid curves correspond to the limit stress ratio $\sigma_{\lim } / \sigma_{\mathrm{cr}}$. To aid comparison between the six diagrams, the normal stress $\sigma(\theta)$ axes have the same vertical scale ${ }^{2}$. From observation of Fig. 10 the following remarks can be made:

\footnotetext{
2 To better distinguish between the several coloured curves (applied stress levels), the interested reader is referred to the electronic version of the present paper (pdf file).
} 
(i) For $\sigma<\sigma_{\lim }$ and independently of the aspect ratio a/b, the normal stress is uniform along the EHS mid-line (i.e. $\sigma$ is almost independent of $\theta$ ). Further, as also seen in Fig. 5, the stress level corresponding to $\sigma=\sigma_{\text {lim }}$ decreases with increasing aspect ratio a/b. From this observation, it could be interpreted that it is preferable to design EHS with lower aspect ratios - the CHS being the limit configuration. However, as will be seen later, such an approach not truly corresponds to optimum EHS design.

(ii) For $\sigma>\sigma_{\text {lim }}$ and independently of the aspect ratio $a / b$, the normal stress ceases to remain uniform along the EHS mid-line (i.e. $\sigma$ varies with $\theta$ ). However, it should be highlighted that the non-linear distribution of $\sigma(\theta)$ varies markedly with aspect ratio a/b.

(ii.1) The zones of maximum EHS radius of curvature $\left(\theta=90^{\circ}\right.$ and $\left.270^{\circ}\right)$ are always in compression $(\sigma(\theta)>0)$ but the normal stress decreases continuously for increasing applied stress ratio $\left(\sigma / \sigma_{\mathrm{cr}}\right)$. This evidence is common to all diagrams and, thus, is a characteristic of all tubes, independent of the aspect ratio a/b. Moreover, it may also be seen that there are two ranges of $\theta$ (near $\theta=90^{\circ}$ and $270^{\circ}$ ) where the stress is almost uniform for the maximum axial shortening (black lines). These ranges are approximately $60^{\circ}<\theta<120^{\circ}$ and $240^{\circ}<\theta<300^{\circ}$, and do not depend to a large extent on the aspect ratio $a / b$.

(ii.2) The points of minimum EHS radius of curvature $\left(\theta=0^{\circ}\right.$ and $\left.180^{\circ}\right)$ may be in compression or in tension, and this fact has far reaching implications for the stability of the post-buckling branches. Immediately after the peak $\left(\sigma_{\lim }\right)$, the normal stress in the $\theta=0^{\circ}$ and $180^{\circ}$ regions decrease for all a/b values; this decrease being much more pronounced for moderate to low aspect ratios $(\mathrm{a} / \mathrm{b} \leq$ 1.5) than for moderate to high aspect ratio $(a / b \geq 2.0)$. For $a / b=1.10$, the stress decreases and changes sign, with the points of minimum EHS radius of curvature $\left(\theta=0^{\circ}\right.$ and $\left.180^{\circ}\right)$ being in tension at the maximum axial shortening (black line). For $1.25 \leq \mathrm{a} / \mathrm{b} \leq 2.0$, the stress decreases and changes sign, but then tends to increase again with increasing displacement. For $3.0 \leq \mathrm{a} / \mathrm{b} \leq 5.0$, the stress slightly decreases after the peak but then increases significantly, and the points $\theta=0^{\circ}$ and $180^{\circ}$ are never in tension. The points of maximum compressive stress are not at the minimum EHS radius of curvature $\left(\theta=0^{\circ}, 180^{\circ}\right)$ but are immediately adjacent to these points at $\theta=10-30^{\circ}, 150-170^{\circ}, 190-210^{\circ}$ and 330 $350^{\circ}$. 
(iii) As noted above, non-linear distributions of $\sigma(\theta)$ vary markedly with aspect ratio $a / b$. For low to moderate aspect ratios $(\mathrm{a} / \mathrm{b} \leq 1.5)$, the stress distribution in the zones of minimum EHS radius of curvature $\left(\theta<60^{\circ}, 120^{\circ}<\theta<240^{\circ}, \theta>300^{\circ}\right)$ is distinctly non-linear with $\theta$, with compressive and tensile stresses occurring over different ranges of $\theta$. For increasing aspect ratio $(\mathrm{a} / \mathrm{b} \geq 1.5)$, the stress distribution in the zones of minimum EHS radius of curvature $\left(\theta<60^{\circ}, 120^{\circ}<\theta<240^{\circ}, \theta>300^{\circ}\right)$ becomes more uniform. This may be seen most clearly for the EHS tube with $\mathrm{a} / \mathrm{b}=5$, where the compressive stresses are almost uniform inside the ranges $\theta<60^{\circ}, 120^{\circ}<\theta<240^{\circ}$ and $\theta>300^{\circ}$, for the maximum axial shortening (black line).

(iv) For EHS tubes with low eccentricity (or aspect ratio a/b), the development of tension stresses in the zones of minimum EHS radius of curvature lead to a "softening effect" in behaviour of the tube, since the average stress along the EHS mid-line (which equals the average applied stress $\sigma$ ) as the tensile stresses grow. This is the reason for the almost horizontal post-buckling branches following the initial drop in load (see Fig. 6) exhibited by the EHS tubes with $\mathrm{a} / \mathrm{b}=1.1$ and 1.25 ; their post-buckling behaviour is similar to that exhibited by circular shells (or CHS tubes) and they do not possess any post-critical stiffness. Conversely, for EHS tubes with moderate to high eccentricity (or aspect ratio $\mathrm{a} / \mathrm{b}$ ), the development of high compressive stresses in the zones of minimum EHS radius of curvature lead to a "hardening effect" in behaviour of the tube, since the average stress along the EHS mid-line now tends to increase as the compressive stresses grow. This is the reason for the ascending and stable post-buckling branches (see Fig. 6) exhibited by the of EHS tube with $\mathrm{a} / \mathrm{b}=1.5,2.0,3.0$ and 5.0. Consequently, their postbuckling behaviour is closer to that exhibited by flat plates and they do possess notable post-critical stiffness.

(v) The above described behaviour may be visualized clearly in Fig. 11, where the normal stress distributions $\sigma(\theta)$ corresponding to an axial shortening $\mathrm{u} \approx 15 \mathrm{~mm}$ for the six different aspect ratios $a / b$, are shown. It is clear that, for increasing aspect ratio, the compressive stresses grow and accumulate near the zones of minimum radius of curvature $\left(\theta<60^{\circ}, 120^{\circ}<\theta<240^{\circ}, \theta>300^{\circ}\right)$ while the zones of maximum radius $\left(60^{\circ}\right.$ $<\theta<120^{\circ}$ and $240^{\circ}<\theta<300^{\circ}$ ) possess an approximately uniform and relatively low compressive stress level. Fig. 12 shows that the increase of the compressive stress at $\theta=$ $0^{\circ}\left(\sigma_{\theta=0^{\circ}}\right)$ with the applied stress $\sigma$, shown in Fig. 12(b), is much more prominent than its $\theta=90^{\circ}\left(\sigma_{\theta=90^{\circ}}\right)$ counterpart shown in Fig. 12(a). On the basis of the above findings, it 
may be concluded that an approach based on the "effective width concept", widely used for the strength analysis of flat plates, may be adapted to the design of EHS tubes with moderate to high aspect ratios. This procedure is outside of the scope of the present paper dealing with pure elastic post-buckling, but it is under investigation by the authors (Silvestre and Gardner 2009). 

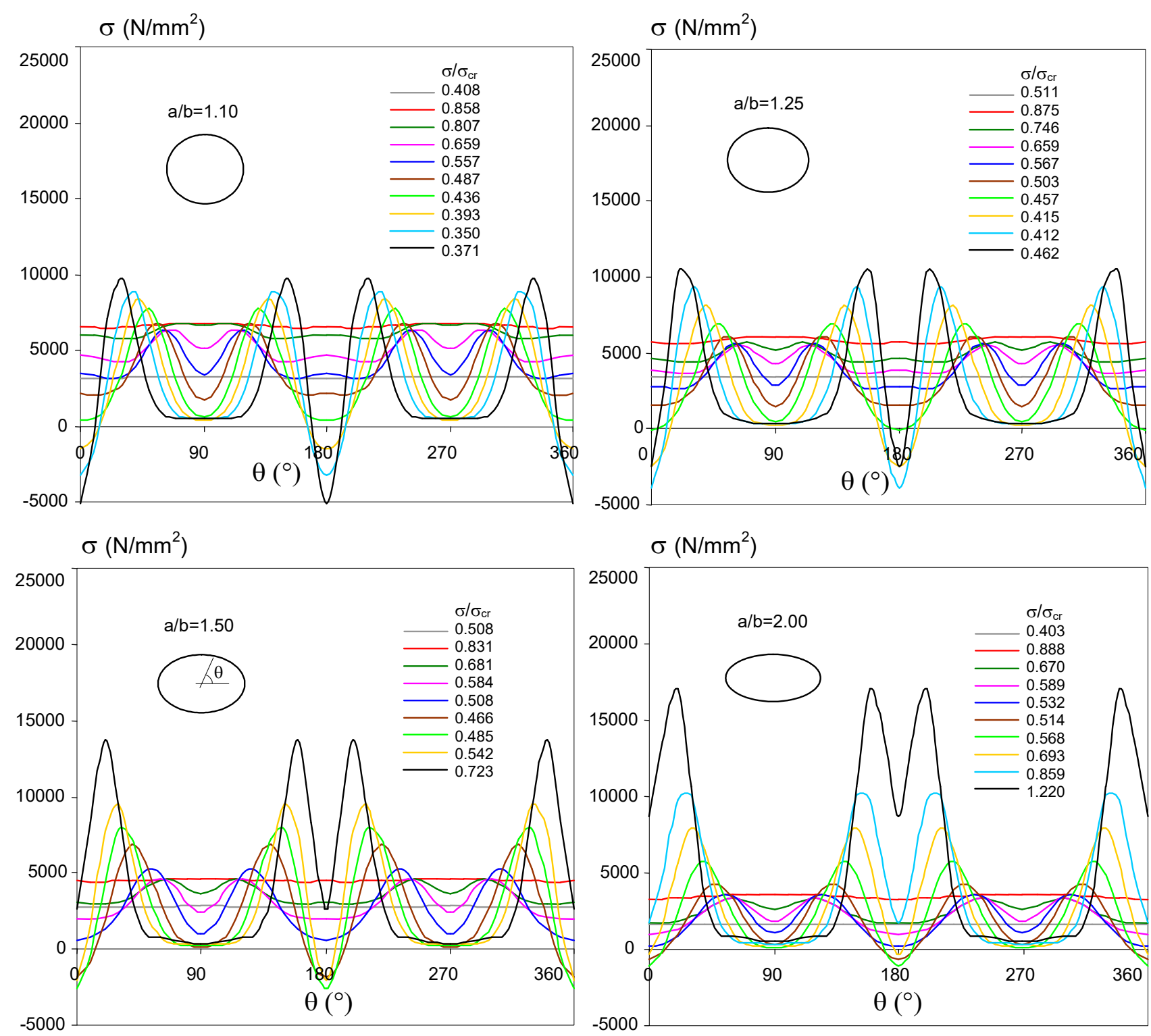

$\sigma\left(\mathrm{N} / \mathrm{mm}^{2}\right)$

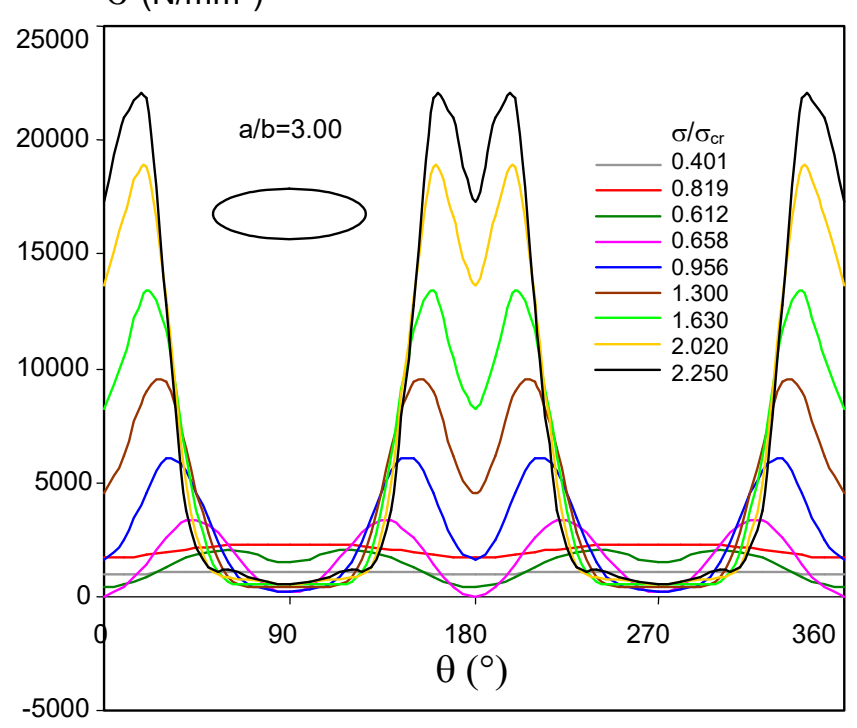

$\sigma\left(\mathrm{N} / \mathrm{mm}^{2}\right)$

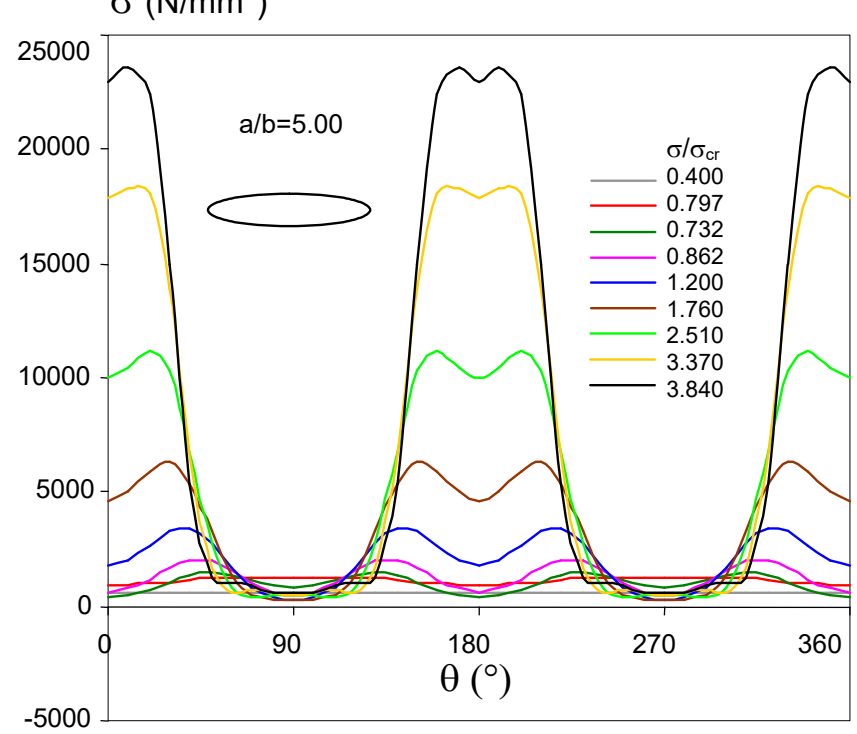

Fig. 10: Evolution of normal stress distributions $\sigma(\theta)$ along the equilibrium paths $\left(\sigma / \sigma_{\mathrm{cr}}\right)$ for the six different aspect ratios $a / b$. 


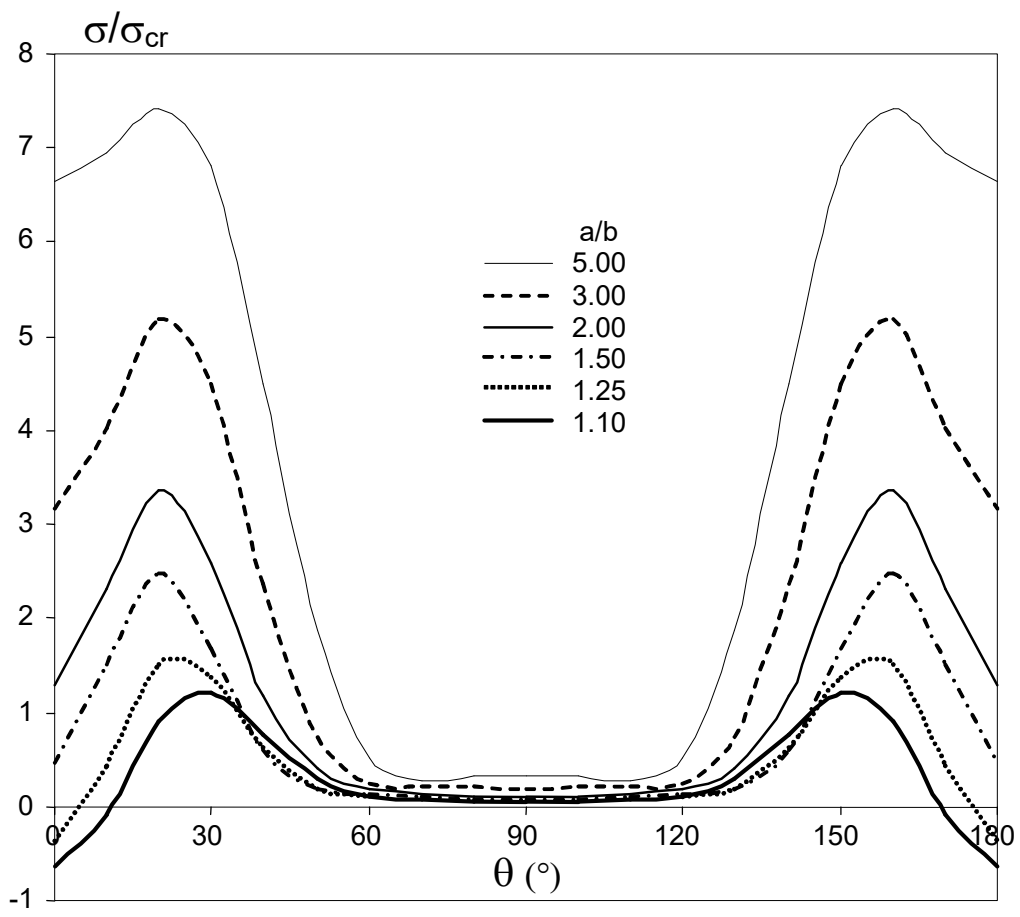

Fig. 11: Normal stress distributions $\sigma(\theta)$ corresponding to an axial shortening $\mathrm{u} \approx 15 \mathrm{~mm}$ for the six different aspect ratios $\mathrm{a} / \mathrm{b}$.
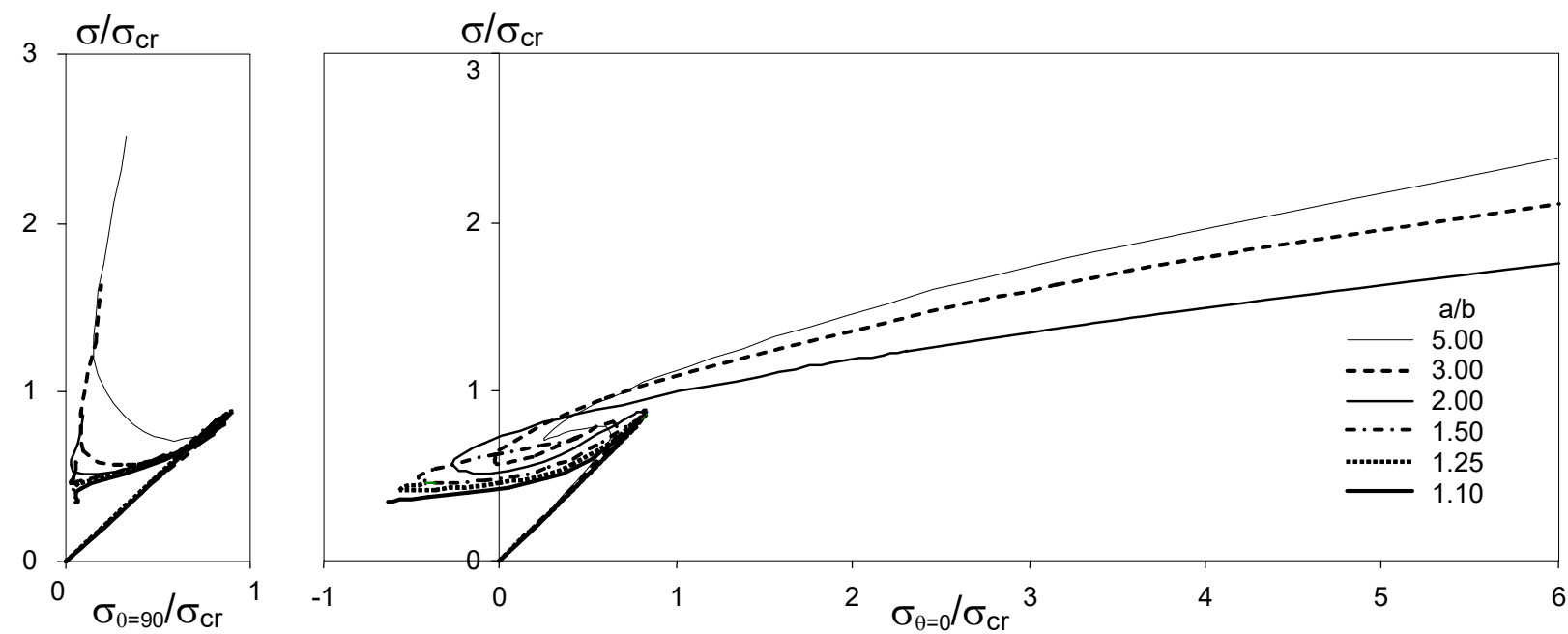

Fig. 12: Evolution of normal stress $\sigma_{\theta}$ (at point $\theta$ ) with the applied stress ratio $\left(\sigma / \sigma_{\mathrm{cr}}\right)$ for the six different aspect ratios a/b: (a) $\theta=90^{\circ}$, (b) $\theta=0^{\circ}$.

\subsection{Imperfection sensitivity}

In previous sections, a constant imperfection amplitude of $2.5 \%$ of the section thickness has been adopted. In this section, imperfection sensitivity of EHS tubes under compression is examined. Each of the six tubes was analysed for six imperfection amplitudes: $\xi=0.04 \mathrm{~mm}$ ( $1 \%$ of the thickness), $\xi=0.10 \mathrm{~mm}$ ( $2.5 \%$ of the thickness), $\xi=0.4 \mathrm{~mm}(10 \%$ of the thickness), $\xi=1.0 \mathrm{~mm}(25 \%$ of the thickness), $\xi=2.0 \mathrm{~mm}$ (50\% of the thickness) and $\xi=4.0 \mathrm{~mm}(100 \%$ of 
the thickness). For the tube with $a / b=2$, Fig. 13 shows the equilibrium paths (critical stress ratio $\sigma / \sigma_{\mathrm{cr}}$ versus axial shortening $\mathrm{u}$ ) obtained for the several imperfection amplitudes. It is clear that, for imperfection amplitudes lower than $25 \%$ of the thickness, the equilibrium paths possess a limit point, and the limit stress $\sigma_{\lim }$ decreases significantly with increasing imperfection amplitude. Conversely, for imperfection amplitudes higher than $50 \%$ of the tube thickness, (i) the equilibrium paths always ascend and (ii) there is no limit stress. This behavioural aspect has far reaching implications for the imperfection sensitivity of EHS tubes: due to its stable and ascending post-buckling branch, a moderately (or highly eccentric) EHS tube may or may not be imperfection sensitive depending on the range of imperfections being considered. For a given aspect ratio $a / b$, there is always a "bound imperfection amplitude" $\left(\xi_{\mathrm{b}}\right)$ that separates the ranges of imperfection amplitude where the tube is imperfection sensitive $\left(\xi<\xi_{\mathrm{b}}\right)$ and insensitive $\left(\xi>\xi_{\mathrm{b}}\right)$. From Fig. 13, for the EHS tube with $\mathrm{a} / \mathrm{b}=2$, this $\xi_{\mathrm{b}}$ value should lie between $25 \%$ and $50 \%$ of the thickness. Using a trial-and-error procedure, the exact value of the "bound imperfection amplitude" was found to be $\xi_{\mathrm{b}}=1.2 \mathrm{~mm}=30 \%$ of the thickness.

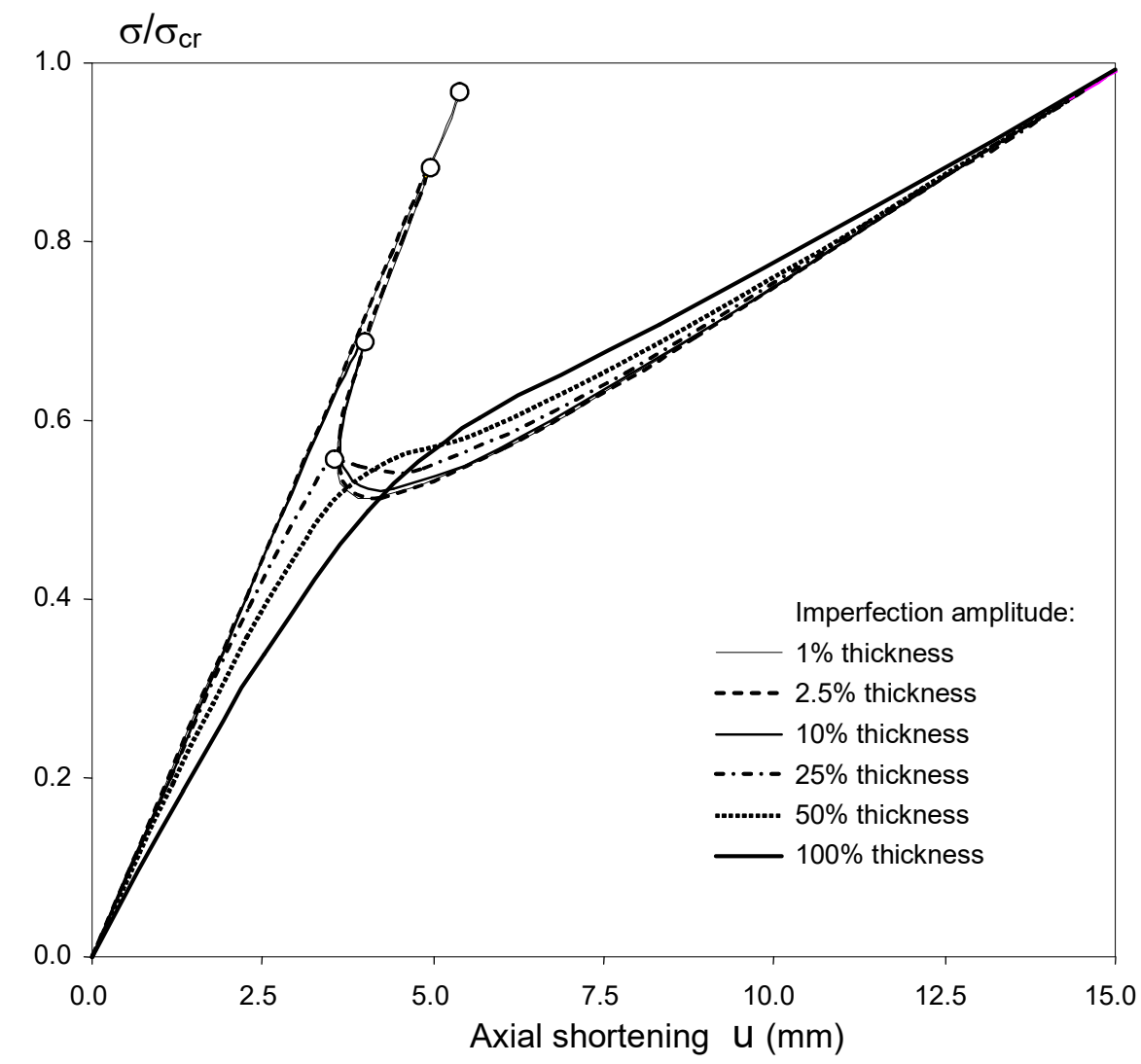

Fig. 13: Relationship between the critical stress ratio $\left(\sigma / \sigma_{\text {cr }}\right)$ and axial shortening $u(f o r a / b=2)$ for a range of imperfection amplitudes. 
Fig. 14 shows, for each aspect ratio $a / b$, the variation of the limit-to-critical stress ratio $\left(\sigma_{\lim } / \sigma_{\mathrm{cr}}\right)$ with the imperfection amplitude $\xi$. The clear circles correspond to the considered imperfection amplitudes $\xi$ while the solid circles correspond to the bound imperfection amplitudes $\xi_{\mathrm{b}}$. Clearly, the $\sigma_{\text {lim }} / \sigma_{\mathrm{cr}}$ values always decrease with increasing imperfection amplitudes, but it is also clear that the range of $\xi$ values over with this drop takes place diminishes for increasing aspect ratio $a / b$. For instance, the highly eccentric tube with $a / b=5$ is sensitive only for very small imperfection amplitudes $\left(\xi<\xi_{\mathrm{b}}=0.12 \mathrm{~mm}\right)$. Fig. 14 also shows that the qualitative shape of the six curves is similar: for instance, the three curves corresponding to $\mathrm{a} / \mathrm{b}=1.1,1.25$ and 1.5 are almost coincident, all close to $\sigma_{\lim } / \sigma_{\mathrm{cr}} \approx 0.50$. On the other hand, the limit-to-critical stress ratio $\left(\sigma_{\lim } / \sigma_{\mathrm{cr}}\right)$ corresponding to the minimum imperfection $\xi=0.04 \mathrm{~mm}$ remains almost unaltered for $\mathrm{a} / \mathrm{b} \leq 2$ but slightly decreases for $\mathrm{a} / \mathrm{b}$ $\geq 3$.
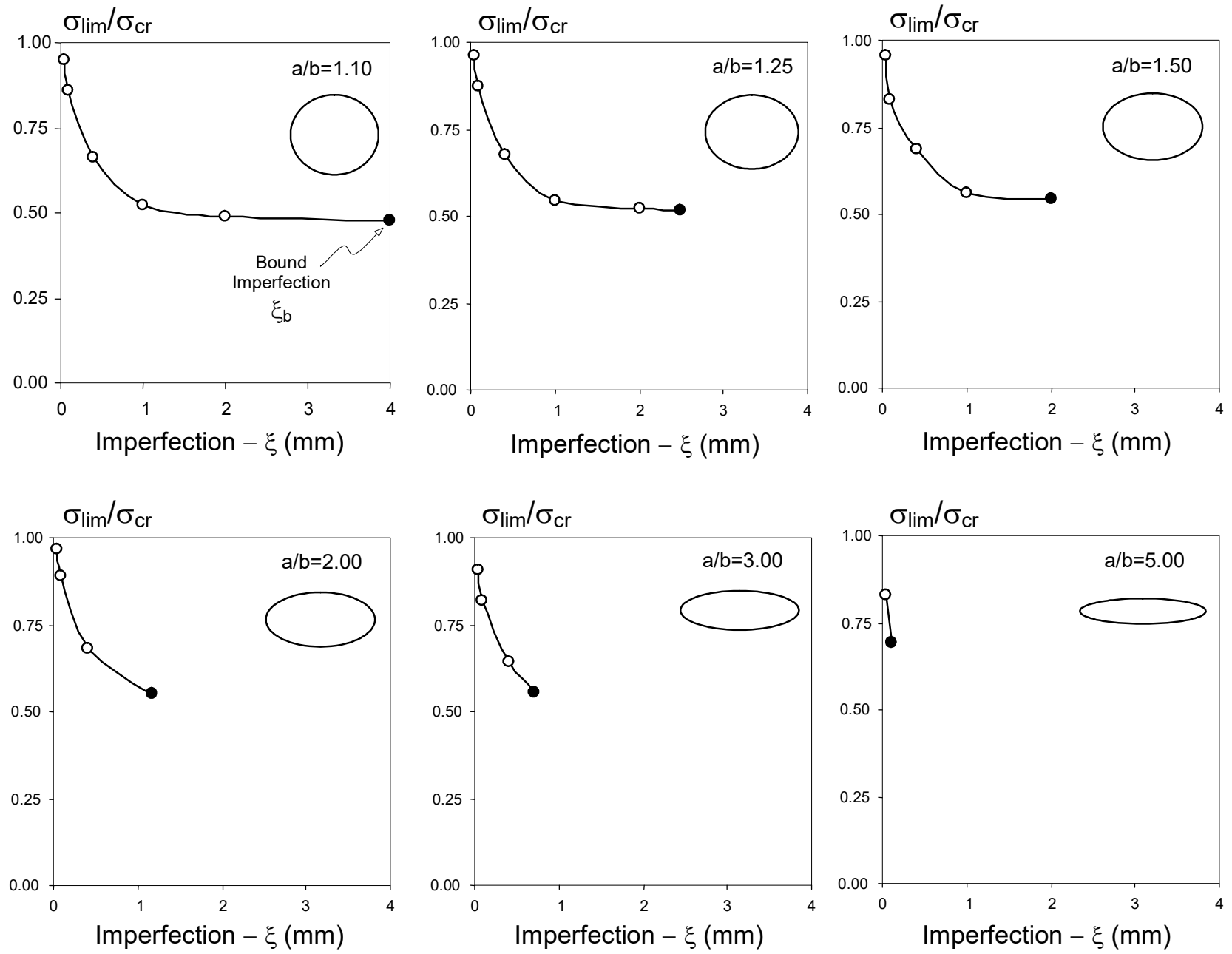

Fig. 14: Variation of the limit to critical stress ratio $\left(\sigma_{\lim } / \sigma_{\mathrm{cr}}\right)$ with imperfection amplitude $\xi$, for different aspect ratios $\mathrm{a} / \mathrm{b}$. 
Figs. 15(a) and 15(b) show the variation of the bound values of the imperfection amplitude $\xi_{\mathrm{b}}$ and limit-to-critical stress ratio $\left(\sigma_{\lim } / \sigma_{\mathrm{cr}}\right)$ b, respectively, with aspect ratio a/b. From Fig. 15(a), it may be seen that the value of bound imperfection amplitude $\xi_{\mathrm{b}}$ solid circles decreases strongly with increasing aspect ratio $\mathrm{a} / \mathrm{b}$ and the following approximate expression,

$$
\xi_{b}=t\left(\frac{b}{a}\right)^{2}
$$

gives a prediction of the bound imperfection amplitude that separates the domain of imperfection sensitive $\left(\xi<\xi_{\mathrm{b}}\right)$ and insensitive $\left(\xi>\xi_{\mathrm{b}}\right)$ EHS tubes. Clearly, as a/b tends to infinity, the EHS tube is similar to a flat plate; for such a case, Eq. (8) suggests that $\xi_{\mathrm{b}}=0$ and the structure is always imperfection insensitive $\left(\xi>\xi_{\mathrm{b}}\right)$. Conversely, when $\mathrm{a} / \mathrm{b}$ equal to unity, the EHS tube becomes a CHS and Eq. (8) suggests that $\xi_{\mathrm{b}}=\mathrm{t}$ and the structure is imperfection sensitive when $\xi<\mathrm{t}$. This bound, derived for elastic tubes with radius-to-thickness ratio $\mathrm{R} / \mathrm{t}=$ 15 is not dissimilar to that found by Hong and Teng (2008) for very thin circular cylindrical shells $(\mathrm{R} / \mathrm{t}=400)$, where an imperfection amplitude approaching half the wall thickness $\left(\xi_{\mathrm{b}}=\right.$ $0.5 \mathrm{t}$ ) was observed to lead to a stable post-buckling path for any applied stress level. Given that the R/t ratio of Hong and Teng's study is significantly higher than that of the present study, it is believed that these bound imperfection amplitudes $\left(\xi_{\mathrm{b}}=\mathrm{t}\right.$ and $\left.\xi_{\mathrm{b}}=0.5 \mathrm{t}\right)$ may be considered to be in reasonable agreement. Furthermore, by observing Fig. 14 for $\mathrm{a} / \mathrm{b}=1.1$, it is found that the $\sigma_{\lim } / \sigma_{\mathrm{cr}}$ values for $\xi=0.5 \mathrm{t}=2 \mathrm{~mm}$ and $\xi=\xi_{\mathrm{b}}=\mathrm{t}=4 \mathrm{~mm}$ only differ by the very small amount: $\sigma_{\lim } / \sigma_{\mathrm{cr}}=0.48$ and 0.49 for $\xi=0.5 \mathrm{t}=2 \mathrm{~mm}$ and $\xi=\xi_{\mathrm{b}}=\mathrm{t}=4 \mathrm{~mm}$, respectively. From Fig. 15(b), it may be observed that the variation of the bound value of $\sigma_{\lim } / \sigma_{\mathrm{cr}}$, i.e. $\left(\sigma_{\mathrm{lim}} / \sigma_{\mathrm{cr}}\right) \mathrm{b}$, with aspect ratio a/b is approximately linear and with a relatively small slope. From the presented results and observation mentioned above, it is clear that the imperfection sensitivity of EHS tubes significantly drops for increasing aspect ratio with a transition from shell-type behaviour (strongly imperfection sensitive) to plate-type behaviour (imperfection insensitive). 

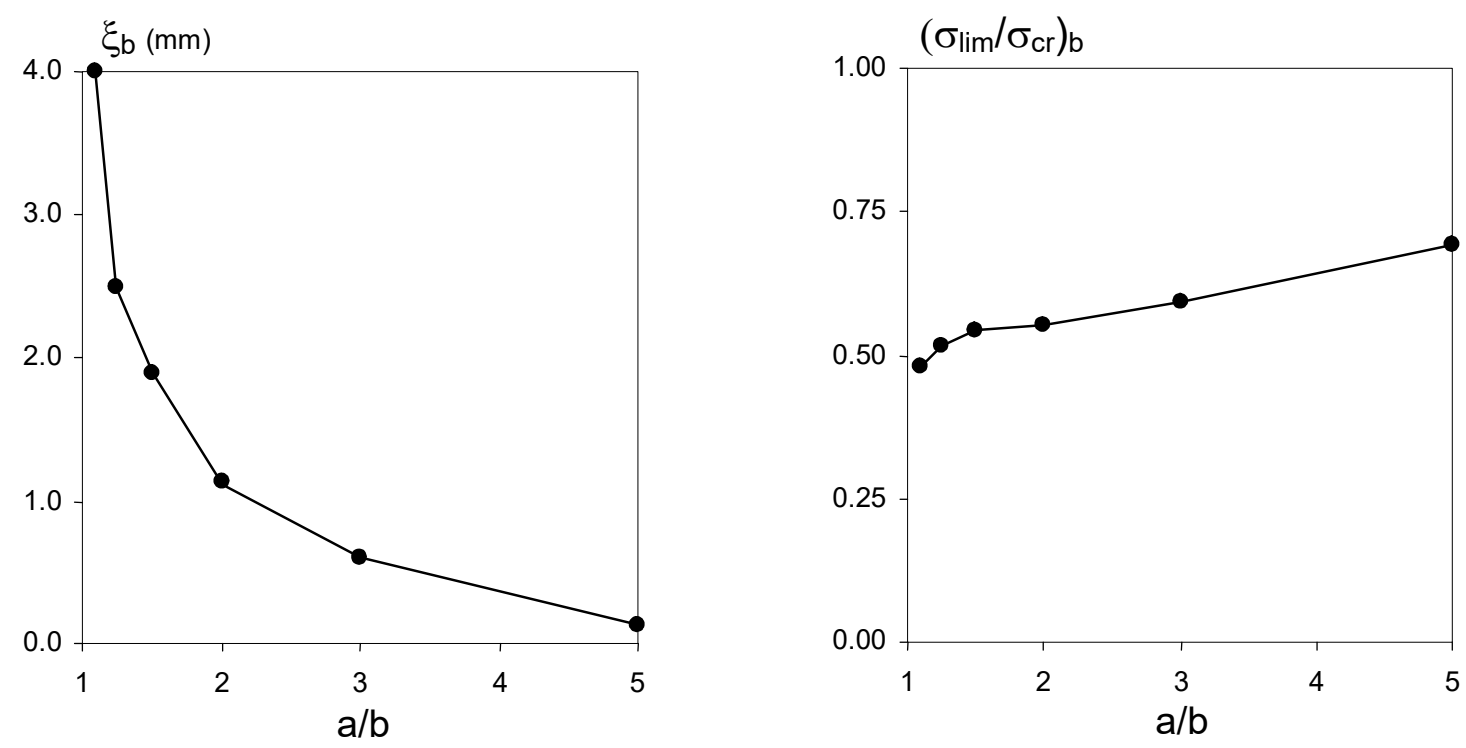

Fig. 15: Variation of the bound values of the (a) imperfection amplitude and (b) limit-to-critical stress ratio $\left(\sigma_{\lim } / \sigma_{\mathrm{cr}}\right)$ with aspect ratio.

\section{Conclusions}

The elastic local post-buckling behaviour of tubes with elliptical hollow sections (EHS) under compression was analysed in this paper. Initially, a brief overview of the local, distortional and global buckling behaviour of EHS tubes was presented, showing that the local buckling modes govern the stability of short to intermediate length tubes while distortional modes control the stability of intermediate length to moderately long tubes and global flexural buckling dominates for long tubes. From previous investigations, some conclusions were drawn concerning the influence of the key geometrical parameters (aspect ratio and local slenderness) on the EHS local critical stress. Following this, an in-depth numerical study on the elastic local post-buckling behaviour of compressed EHS tubes was presented. Firstly, the shell finite element model was described, namely the finite element discretisation, the member end support conditions, the loading and material properties, the initial imperfections and the numerical solution technique. The obtained numerical results were then presented and analysed; the following conclusions are drawn:

(i) Non-linear equilibrium paths - The maximum applied stress that an elastic EHS tube with low to moderate aspect ratio $(\mathrm{a} / \mathrm{b} \leq 1.5)$ can support is its limit stress $\sigma_{\text {lim, while the }}$ maximum applied stress that an elastic EHS tube with moderate to high aspect ratio $(\mathrm{a} / \mathrm{b}$ $\geq 2.0$ ) can carry is higher than its limit stress $\sigma_{\text {lim. }}$. It was observed that the slope of the ascending branch increases with aspect ratio a/b and can reach values up to $40 \%$ of the initial slope of the linear primary path. 
(ii) Normal stress distributions - For increasing aspect ratio $\mathrm{a} / \mathrm{b}$, the compressive stresses grow and accumulate near the zones of minimum radius of curvature while the zones of maximum radius of curvature possess an approximately uniform and relatively low compressive stress level. Therefore, it is expected that an approach based on the "effective width concept" widely used for the strength analysis of flat plates may be adapted to the design of EHS tubes with moderate to high aspect ratio.

(iii) Imperfection sensitivity - For a given aspect ratio $a / b$, there is a "bound imperfection amplitude" $\xi_{\mathrm{b}}$ that separates the ranges of imperfection amplitude where the EHS tube is imperfection sensitive $\left(\xi<\xi_{\mathrm{b}}\right)$ and insensitive $\left(\xi>\xi_{\mathrm{b}}\right)$. Moreover, it was shown that the imperfection sensitivity of EHS tubes significantly drops for increasing aspect ratio $a / b$, ranging between shell-type behaviour (strongly imperfection sensitive) and plate-type behaviour (imperfection insensitive).

The present study on the local post-buckling behaviour of EHS tubes assumes elastic material behaviour. Further studies to investigate the effect of material yielding on the local postbuckling behaviour of EHS tubes, including the development of strength curves based on an effective width approach, are currently underway. 


\section{References}

CEN - Comité Européen de Normalisation (2007). EN 1993-1-6: Eurocode 3 - Design of steel structures, Part 1.6: General rules - Strength and stability of shell structures.

CEN - Comité Européen de Normalisation (2006). EN 10210-2: Hot finished structural hollow sections of non-alloy and fine grain steels - Part 2: Tolerances, dimensions and sectional properties.

Chan T.M., Gardner L. (2008). Compressive resistance of hot-rolled elliptical hollow sections. Engineering Structures 30(2), 522-532.

Chan, T. M., Gardner, L. (2009). Flexural buckling of elliptical hollow section columns. Journal of Structural Engineering-ASCE 135(5), 546-557.

Corus (2006). Celsius 355s Ovals. Internet:

http://www.corusgroup.com/en/products/tube_products/structural_hollow_sections/hot finished/celsius_ovals

DS Simulia Inc. (2007), ABAQUS Standard (version 6.7).

Feinstein G., Chen Y.N., Kempner J. (1971a). Buckling of clamped oval cylindrical shells under axial loads, AIAA Journal 9(9), 1733-1738.

Feinstein G., Erickson B., Kempner J. (1971b). Stability of oval cylindrical shells, Journal of Experimental Mechanics 11(11), 514-520.

Gardner, L., Chan, T. M. (2007). Cross-section classification of elliptical hollow sections. Steel and Composite Structures. 7(3), 185-200.

Hong T., Teng J.G. (2008). Imperfection sensitivity and postbuckling analysis of elastic shells of revolution, Thin-Walled Structures, 46(12), 1338-1350.

Hutchinson J.W. (1968). Buckling and initial postbuckling behaviour of oval cylindrical shells under axial compression, Journal of Applied Mechanics (Transactions ASME) 35(1), 66-72.

Kempner J., Chen Y.N. (1964). Large deflections of an axially compressed oval cylindrical shell, Proceedings of the $11^{\text {th }}$ International Congress on Applied Mechanics, Springer-Verlag: Berlin, 299-306.

Interpipe - The Hollow Section Company (2007). Elliptical Hollow Sections to S355 J2H, Internet: http://www.interpipe.co.uk/users/size_ellip.htm 
Kempner J., Chen Y.N. (1968). Post-buckling of an axially compressed oval cylindrical shell. Proceedings of the $12^{\text {th }}$ International Congress of Applied Mechanics, Stanford University, 246-256.

Marguerre K. (1951). Stability of cylindrical shells of variable curvature, NACA TM 1302.

Roufegarinejad A., Bradford M.A. (2007). Local buckling of thin-walled elliptical tubes containing an elastic infill, Proceedings of the Third International Conference on Steel and Composite Structures (ICSCS07), Y. C Wang, C.K. Choi (Eds), Taylor and Francis, London, 943-948.

Ruiz-Teran A.M., Gardner L. (2008). Elastic buckling of elliptical tubes, Thin-Walled Structures 46(11), 1304-1318.

Silvestre N. (2008). Buckling behaviour of elliptical cylindrical shells and tubes under compression, International Journal of Solids and Structures, 45(16), 4427-4447.

Silvestre N., Gardner L. (2009). Strength curves for elliptical tubes, in preparation.

Tennyson R.C., Booton M., Caswell R.D. (1971). Buckling of imperfect elliptical cylindrical shells under axial compression, AIAA Journal 9(2), 250-255.

Tvergaard V. (1976). Buckling of elastic-plastic oval cylindrical shells under axial compression, International Journal of Solids and Structures 12(9-10), 683-691.

Yang, H., Lam, D., Gardner, L. (2008). Testing and analysis of concrete-filled elliptical hollow sections. Engineering Structures. 30(12), 3771-3781.

Zhao, X. L., Packer, J. A. (2009). Tests and design of concrete-filled elliptical hollow section stub columns, Thin-Walled Structures 47(6-7), 617-628.

Zhu Y., Wilkinson T. (2007). Finite element analysis of structural steel elliptical hollow sections in compression, Research Report No R874, Centre for Advanced Structural Engineering, The University of Sydney. 